\title{
Relative humidity impact on aerosol parameters in a Paris suburban area
}

\author{
H. Randriamiarisoa ${ }^{1}$, P. Chazette ${ }^{1}$, P. Couvert ${ }^{1, \dagger}$, J. Sanak ${ }^{1}$, and G. Mégie ${ }^{2, \dagger \dagger}$ \\ ${ }^{1}$ Laboratoire des Sciences du Climat et de l'Environnement/Institut Pierre-Simon Laplace, Orme des Merisiers Bât 701, \\ C.E.Saclay, 91191 Gif-sur-Yvette Cedex, France \\ ${ }^{2}$ Service d'Aéronomie/Institut Pierre-Simon Laplace, 4 place Jussieu, 75252 Paris, France \\ $\dagger$ deceased, June 2005 \\ $\dagger$ deceased, June 2004
}

Received: 11 January 2005 - Published in Atmos. Chem. Phys. Discuss.: 5 September 2005

Revised: 18 January 2006 - Accepted: 22 February 2006 - Published: 2 May 2006

\begin{abstract}
Measurements of relative humidity (RH) and aerosol parameters (scattering cross section, size distributions and chemical composition), performed in ambient atmospheric conditions, have been used to study the influence of relative humidity on aerosol properties. The data were acquired in a suburban area south of Paris, between 18 and 24 July 2000, in the framework of the "Etude et Simulation de la Qualité de l'air en Ile-de-France" (ESQUIF) program. According to the origin of the air masses arriving over the Paris area, the aerosol hygroscopicity is more or less pronounced. The aerosol chemical composition data were used as input of a thermodynamic model to simulate the variation of the aerosol water mass content with ambient $R H$ and to determine the main inorganic salt compounds. The coupling of observations and modelling reveals the presence of deliquescence processes with hysteresis phenomenon in the hygroscopic growth cycle. Based on the Hänel model, parameterisations of the scattering cross section, the modal radius of the accumulation mode of the size distribution and the aerosol water mass content, as a function of increasing $\mathrm{RH}$, have been assessed. For the first time, a crosscheck of these parameterisations has been performed and shows that the hygroscopic behaviour of the accumulation mode can be coherently characterized by combined optical, size distribution and chemical measurements.
\end{abstract}

\footnotetext{
Correspondence to: P. Chazette

(patrick.chazette@cea.fr)
}

\section{Introduction}

Water is the main solvent for constituents of atmospheric aerosol particles. The affinity of these aerosol particles to water, via the ambient relative humidity $\mathrm{RH}$, plays an important role in several processes. It may influence the visibility reduction in the atmosphere (e.g. Tang et al., 1981), the aerosol gas chemistry through multiphase reactions (e.g. Larson and Taylor, 1983; Rood et al., 1987) and the particles ability to act as cloud condensation nuclei (e.g. Kulmala et al., 1993).

Moreover, aerosol hydration has important consequences on the Earth's radiation budget (Covert et al., 1979; Tang et al., 1981; Boucher and Anderson, 1995; Hobbs et al., 1997). To date, this aspect is poorly or not parameterised in climate and photochemical models and it still constitutes one of the largest sources of uncertainties in aerosol radiative impacts modelling (IPCC, 2001). Haywood et al. (1997) demonstrated that the spatial resolution of the atmospheric $R H$ field can lead to significant biases in the radiative forcing estimates. Adams et al. (1999) found that the large amount of water taken up by the aerosol above $95 \%$ of $R H$ might increase the total aerosol radiative forcing by about $60 \%$. Hence, it is a factor to be kept in mind when attempting to verify model estimates with observations. Van Dorland et al. (1997) estimated also that global and annual average direct radiative forcing from sulphate aerosols is $-0.36 \mathrm{~W} . \mathrm{m}^{-2}$, when assuming a uniform relative humidity $R H \sim 80 \%$ and is only $-0.32 \mathrm{~W} . \mathrm{m}^{-2}$ when local variations in $R H$ are considered. Studies led by Kotchenruther et al. (1999) showed as well that an aerosol particle present in the East coast of United States at $R H \sim 80 \%$ is at least twice more efficient in radiative forcing than when the aerosol is at RH 30\%. 
An aerosol particle reacts differently in presence of humidity, ranging from a hydrophobic behaviour to a hygroscopic one. There are two types of hygroscopic properties: monotonic when the particle reacts continuously for all $R H$ values, and deliquescent when the particle remains practically dry up to a certain $R H$ value, called the deliquescence point, where a phase transition occurs from solid to liquid. Moreover, the aerosol properties (size distribution, optical parameters) can evolve differently when $R H$ increases then decreases over time, describing a hysteresis cycle (e.g. Rood et al., 1987, Santarpia et al., 2004). Such a phenomenon can affect the assessment of the aerosol radiative impact. Boucher and Anderson (1995) have performed simulations with anthropogenic sulphate aerosols and have shown that if optical properties are taken from the metastable leg of the hysteresis curve, the global forcing may be about $20 \%$ larger than if the stable leg of the cycle is used.

Aerosol hydration is studied through the behaviour of its optical properties and size characteristics as a function of $R H$. In most of the literature, such studies are performed in a controlled environment, for example by using specific instruments as an Hygroscopicity Tandem Differential Mobility Analyser (H-TDMA) to control $R H$ (Sekigawa, 1983; McMurry and Stolzenburg, 1989; Zhang et al., 1993; Berg et al., 1998; Swietlicki et al., 2000), with either pure components generated from laboratories or standardized aerosol samples. The aim is to obtain observations at different $R H$ values and at dry conditions $(R H<30 \%)$. Another method consists in running two instruments side-by-side, one at dry conditions and the other at controlled RH (e.g. Malm and Kreidenweis, 1997; Carrico et al., 2000, 2003). Detailed ambient aerosol hydration measurements are very sparse and concern mainly size growth studies (e.g. Ferron et al, 2005, Santarpia et al., 2004).

In the present paper, we study the effect of $\mathrm{RH}$, over a wide range, on various aerosol parameters with the particularity to work entirely with measurements performed in ambient atmosphere, without major modification of the aerosol properties. We used data measured at Saclay, a suburban area $25 \mathrm{~km}$ south of Paris. In Sect. 2, the instruments and the measured parameters are presented. Section 3 focuses on the direct observations of the $R H$ effect on the measured aerosol cross-section and the retrieved aerosol size distribution. In some cases under study, the sensitivity of the data to $R H$ suggests a hysteresis phenomenon. To further understand the data, the aerosol chemical composition is analysed in Sect. 4. A modelling approach has also been performed to simulate the salts contained in the aerosols as well as to retrieve their aerosol water content evolution with $R H$. Following Hänel (1976), parameterisations of the growth with $R H$ of the scattering cross-section, the modal radius of the accumulation mode and the water content of the aerosol are proposed in Sect. 5. The coherence of these different parameterisations is analysed and the existence of the hysteresis phenomenon is established.

\section{Experimental set-up}

Measurements of aerosol parameters were conducted at Saclay, between 18 and 24 July 2000, in the framework of the ESQUIF (Etude et Simulation de la Qualité de l'air en région Ile de France) program. This program's aim was to better understand the processes leading to air pollution peaks in Paris area by combining experimental and modelling approaches (Menut et al., 2000; Vautard et al., 2003a). Saclay $\left(48.73^{\circ} \mathrm{N}, 2.17^{\circ} \mathrm{E}\right)$ is located at $\sim 25 \mathrm{~km}$ south of Paris city and is mainly influenced by anthropogenic pollutant sources from automobile traffic in the Paris area (Menut et al., 2000). To assess the impact of $R H$ on the aerosols, different in situ measurements (scattering coefficient, the size distribution, and the chemical composition of the aerosols) were simultaneously performed.

\subsection{Aerosol scattering coefficient}

A mono-wavelength $(550 \mathrm{~nm})$ nephelometer (MRI integrating nephelometer model 1550B) was used to measure the aerosol scattering coefficient $\alpha_{\text {scatt }}$ in a $7-170^{\circ}$ range of scattering angles. The principle of this instrument is similar to the nephelometer manufactured by TSI (Bodhaine et al., 1991), except that it is not heated and thus operates in ambient relative humidity. We measured differences $<5 \%$ between the relative humidity outside and the relative humidity inside the instrument. To take into account the non-observed scattering angles, a correction factor has been assessed from Mie computations (Chazette et al., 2005) to be close to 1.035 for urban aerosols. The mean relative uncertainty of the nephelometer is considered to be less than 10\% (Bodhaine et al., 1991) mainly due to the variability of the inside $R H$. In dry conditions, the relative uncertainty, after calibration, is of a few percent (evaluated from the reproducibility of laboratory measurements).

\subsection{Aerosol size distribution}

Three complementary types of optical particle counter/sizers instruments were used: a 3022A CPC (TSI model), a $\mathrm{KC18}$ (RION Co, Ltd. Japon) and a MET-ONE (http://www.metone.com). The CPC detects all particles with a radius ranging from 0.005 to $1.5 \mu \mathrm{m}$, with $100 \%$ efficiency for $0.01 \mu \mathrm{m}$. A relative uncertainty of $5 \%$ has been calculated for retrieved aerosol concentrations (Chazette and Liousse, 2001). The KC18 gives access to the partition function of the aerosol in five radii classes: $>0.05 \mu \mathrm{m}$, $>0.075 \mu \mathrm{m},>0.1 \mu \mathrm{m},>0.15 \mu \mathrm{m},>0.25 \mu \mathrm{m}$. The light source is a He-Ne laser and the measurement is performed at a $90^{\circ}$ scattering angle with an inlet air flux rate of $0.301 . \mathrm{mn}^{-1}$. The MET-ONE instrument gives the aerosol partition function in six radii classes: $>0.15 \mu \mathrm{m}$, $>0.25 \mu \mathrm{m},>0.35 \mu \mathrm{m},>0.5 \mu \mathrm{m},>1 \mu \mathrm{m},>1.5 \mu \mathrm{m}$ and uses a diode laser source, with an inlet flow rate of $2.831 . \mathrm{mn}^{-1}$. 
Particles with radius $\sim 0.15 \mu \mathrm{m}$ are detected within $50 \%$ efficiency. The efficiency reaches $100 \%$ for particles larger than $0.25 \mu \mathrm{m}$. After correction of the counting efficiency, the relative error on the measurements from KC18 and MET-ONE is $\sim 5$ to $10 \%$. Such an error is mainly a function of the difference between the aerosol refractive index considered for the manufacture calibration and the one of the ambient particles as shown by Hand and Kreidenweis (2002).

A standard method using a proximity recognition approach (e.g. Chazette et al., 2005) was used to retrieve the aerosol size distribution $\rho_{N}(r)$, assuming 3 modes (nucleation, accumulation and coarse) with a lognormal distribution. The method consists in best fitting the particle numbers in the nine classes deduced from the $\mathrm{KC} 18$, the MET-ONE and the CPC measurements. The distribution $\rho_{N}(r)$ is characterized by the modal radius $\left(r_{N 1}, r_{N 2}, r_{N 3}\right)$, the geometric standard deviations $\left(\sigma_{N 1}, \sigma_{N 2}, \sigma_{N 3}\right)$ and the fractional number concentrations $\left(x_{N 1}, x_{N 2}, x_{N 3}\right.$, with $\sum_{i=1}^{3} x_{N i}=1, x_{N i}$ is the proportion of particles in the mode $i, x_{N i}<1$ ).

\subsection{Aerosol chemical composition}

Ten aerosol samples devoted to carbonaceous analyses were collected during the period under study (18-24 July, 2000), using a low volume sampler $\left(3 \mathrm{~m}^{3} \cdot \mathrm{h}^{-1}\right)$ on pre-cleaned Whatman GF/F glass-fibber filters. The carbon mass was determined through a thermal protocol, defined by Cachier et al. (1989), which separates the black carbon (BC) and the organic carbon (OC) masses. The precision of the results is estimated to be of the order of $10 \%$. The accuracy of the method linked to the thermal separation of both carbonic components is close to 20\% (Brémond et al., 1989). Particulate organic matter (POM) dry mass concentration is calculated from the relationship given by Countess et al. (1980) and adapted by Liousse et al. (1996):

$\mathrm{POM}=1.3 \mathrm{OC}$.

The value of the OC to POM factor could significantly vary. Values between 1.2 and 1.7 are generally used (Hegg et al., 1997; Turpin et al., 2000). The relative uncertainty on this factor is $\sim 31 \%$ as given by Turpin and Lim (2001).

Ten nuclepore membranes were also mounted on a stack filter unit in order to separate the coarse and the fine fraction of the inorganic water soluble (WS) portion of the aerosols. The size cut of the membrane is of the order of $1 \mu \mathrm{m}$ in radius (Liu and Lee, 1976). These filters were used to measure the major soluble inorganic ions in the particle by ion chromatography. The precision on ion chromatography analysis has been evaluated to be 5-10\% (Jaffrezo et al., 1994). Total particulate matter (TPM) was obtained with an accuracy of $5 \mu \mathrm{g}$ in a controlled environment with a $R H$ less than $30 \%$. Since no aluminium nor silicon measurements were performed, which could have led to dust concentration, we estimated the aerosol residual fraction, including dust, using the following relationship:

Residual $=\mathrm{TPM}-(\mathrm{BC}+\mathrm{POM}+\mathrm{WS})$.

Such an equation assumes no water is associated with the aerosol at $R H=30 \%$. This point will be considered in the next sections. In order to assess a mass size distribution of the aerosol, we disposed of integrated ground measurements performed between 18 July 09:15 GMT and 21 July 09:40 GMT in inner Paris with a 13 stage DEKATI cascade impactor (http://www.dekati.com). This instrument samples the particles with diameter between $0.03 \mu \mathrm{m}$ and $10 \mu \mathrm{m}$. Losses within the impactor is less than $0.5 \%$ for particles larger than $0.1 \mu \mathrm{m}$ and relatively stable throughout the size range. For particles smaller than $0.1 \mu \mathrm{m}$, losses start to increase rapidly. Each filter for the 13 stages has been analysed by ion chromatography and X-Ray fluorescence, providing mass size distributions of WS and elementary species, respectively. The $\mathrm{BC}$ and $\mathrm{OC}$ concentrations have also been extracted from Whatman GF/F glass-fibber filters.

\subsection{Meteorological parameters}

A humidity sensor (Vaisala, Campbell Scientific Model HMP45A) measured $R H$ values with uncertainties of $\pm 2 \%$ for $R H$ values between $0 \%$ and $90 \%$ and $\pm 3 \%$ for $R H$ values between $90 \%$ and $100 \%$. The wind characteristics were provided by a bi-dimensional sonic anemometer (R. M. Young Model 05103 Wind Monitor) with a precision of $0.01 \mathrm{~ms}^{-1}$ for the intensity and $0.1^{\circ}$ for the direction.

\section{Evidence of $R H$ effect on urban aerosol properties}

\subsection{Direct observations}

In order to counteract the time variability of the total aerosol number concentration $N_{t}$, the aerosol scattering cross section $\sigma_{\text {scatt }}\left(\sigma_{\text {scatt }}=\alpha_{\text {scatt }} / N_{t}\right)$ is hereafter considered rather than using the scattering coefficient $\alpha_{\text {scatt }}$ given by the nephelometer. The time evolution between 18 and 24 July 2000 of $R H(\%)$ and $\sigma_{\text {scatt }}\left(\mathrm{cm}^{2}\right)$ is shown in Fig. 1.

For the following studies, we decided to split the observation period into 5 separate time periods: from 18 July at $20 \mathrm{~h}$ GMT to 19 July at $9 \mathrm{~h}$ GMT (18.9-19.4) noted P1, from 20 July at $0 \mathrm{~h}$ GMT to 20 July at $14 \mathrm{~h}$ GMT (20-20.6) noted P2, from 20 July at $14 \mathrm{~h}$ GMT to 21 July at $19 \mathrm{~h}$ GMT (20.621.8) noted P3, from 21 July at $19 \mathrm{~h} \mathrm{GMT}$ to 22 July at $18 \mathrm{~h}$ GMT (21.8-22.8) noted P4, and from 22 July at $18 \mathrm{~h} \mathrm{GMT}$ to 23 July at $17 \mathrm{~h}$ GMT (22.8-23.7) noted P5. Each period corresponds to a diurnal cycle of increasing then decreasing $\mathrm{RH}$, except for P1 where only the increasing $R H$ part of the measurements were available.

During the timeframe under study, $R H$ varies between $\sim 40$ and $>90 \%$ with a noticeable diurnal cycle. The lowest 


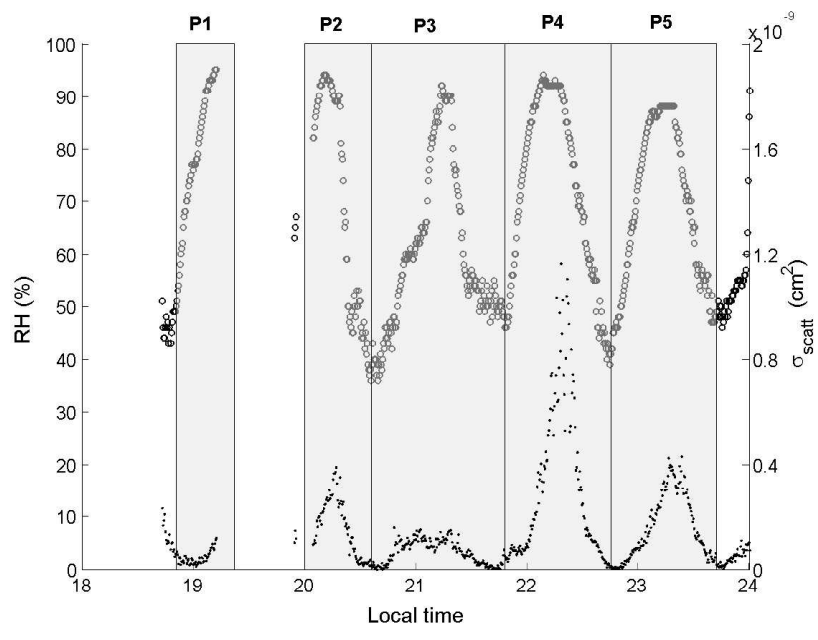

Fig. 1. Time evolution of $R H(\%)$ (open circles) and of the scattering cross section $\sigma_{\text {scatt }}\left(\mathrm{cm}^{2}\right)$ (dots) measured at Saclay between 18 and 24 July, 2000. The grey areas highlight the 5 time periods (P1, P2, P3, P4, and P5) considered in the text.

values are observed in mid afternoon (close to 50\%), while the highest values occur in early morning (close to 95\%). The $\sigma_{\text {scatt }}$ values for the whole timeframe ranged from $2.10^{-12}$ to $1.2 \cdot 10^{-9} \mathrm{~cm}^{2}$, with particularly high values during the daytime of $\mathrm{P} 4$. The $\sigma_{\text {scatt }}$ values recorded for $\mathrm{P} 1$ and $\mathrm{P} 3$, at maximum RH, are significantly lower than for the P2, P4, and P5 periods.

\subsection{Effect of $R H$ on the aerosol scattering cross section}

The aerosol scattering cross section $\sigma_{\text {scatt }}$ as a function of $R H$ is given in Fig. 2 for the 5 time periods P1 to P5. Filled (open) symbols indicate that $R H$ increases (decreases) continuously over the time period of the sampling. Each colour corresponds to one of the ten chemical filters performed during the whole period (see Sect. 4.1). The circle, diamond and star symbols respectively indicate a salt mixture of Type 1, Type 2 and Type 3, as defined in Sect. 4.2.2.

For $\mathrm{P} 1, \sigma_{\text {scatt }}$ is approximately constant except when $R H$ is greater than $90 \%$. For P3, when $R H$ increases or decreases, $\sigma_{\text {scatt }}$ follows the same pattern, suggesting a monotonic hygroscopicity of the aerosols. For P2, P4 and P5, $\sigma_{\text {scatt }}$ reacts more distinctly with $R H$ and the observed patterns are quite different when $R H$ increases and then decreases. Such behaviour looks like a hysteresis effect and may suppose the presence of hygroscopic and deliquescent compounds in the aerosols. Many authors such as Orr et al. (1958), Junge (1963), Tang (1980b), Rood et al. (1987), Nenes et al. (1998), Gasso et al. (2000) have already observed such a complex atmospheric aerosol process. For these three cases $\sigma_{\text {scatt }}$, at high $R H$ (>85-90\%), is a factor of 4 to 10 times larger than for $\mathrm{P} 1$ and $\mathrm{P} 3$ at the same $R H$ values.
Note that the effect of the convection between the surface layer and the mixed layer on our observations is limited because the proximity of the aerosol sources in the urban and suburban areas. Moreover, from airborne lidar measurements (Chazette et al., 2005), we have not observed any correlation between the aerosol optical properties close to the ground and in the mixed layer. Hence, the increasing and decreasing $R H$ experienced by the particles in the mixed layer during upward and downward motion influences the dispersion of the measurements but not significantly the general form of the aerosol property evolutions against $\mathrm{RH}$.

\subsection{Evidence of a deliquescence process}

The Fig. 3a (from Rood et al., 1987) illustrates a deliquescence process with a hysteresis phenomenon for a single pure deliquescent component. Solid arrows correspond to continuous increasing $\mathrm{RH}$, while dashed arrows represent continuous decreasing $R H$. A particle, which is initially dry (stage A), grows rapidly in size due to water condensation at the deliquescence point, noted $D R H$ (beginning of stage B). This point corresponds to the equilibrium water vapour pressure over a saturated aqueous solution formed with the solute and to a phase change, from solid to liquid, of the particle. Beyond $D R H$ (stage C), continuing increase in $R H$ results in further particle size growth, with a sub saturated concentration of the particle solute. When $R H$ decreases under $D R H$ (stage D), the amount of water on the aerosol decreases until the aerosol crystallizes. This typically occurs at the end of stage $\mathrm{E}$, corresponding to the crystallization point noted $C R H$. Table 1 contains values of $D R H$ and $C R H$ for some pure salts at $298 \mathrm{~K}$ (McMurry and Stolzenburg, 1989; Tang and Munkelwitz, 1994; Dougle et al., 1998). Atmospheric aerosols are generally a mixture of several salts and contain more or less insoluble components. The presence of water soluble components in the particle, such as inorganic ions (sulphate, nitrate, ammonium, sodium, chloride...) or organic acids (malonic, glutaric, maleic...) enhance the aerosol hydration, while the presence of insoluble components, such as mineral dust and organic carbon freshly emitted from the sources may inhibit such a process (Charlson et al., 1984; Tang, 1980a; Rood et al., 1987; Saxena et al., 1995; Andrews and Larson, 1993). Certain other authors have not seen any measurable changes in the behaviour of a hygroscopic inorganic core with hydrophobic organic coatings (Hansson et al., 1990; Hameri et al., 1992; Cruz and Pandis, 1998; Kleindienst et al., 1999). In the latter case, we can suppose that a fraction of organic components may be hygroscopic in an organic acid form. There is nonetheless substantial disagreement among authors regarding how much aerosol water uptake may be attributed to organic compounds. Based on thermodynamic calculations, some authors have reported that organics at rural locations may largely contribute to total water uptake (Saxena et al., 1995; Dick et al., 2000). However, other authors have 
(a)
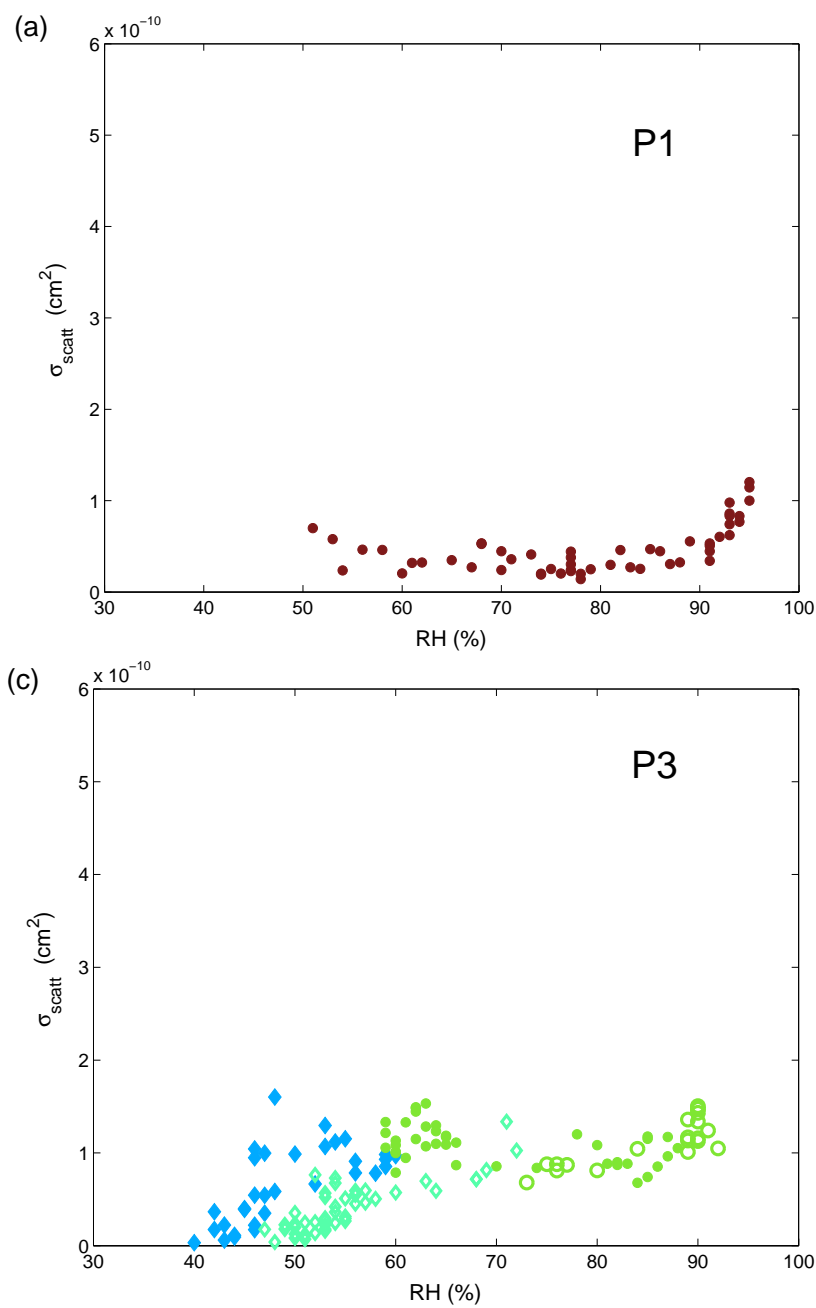

(b)
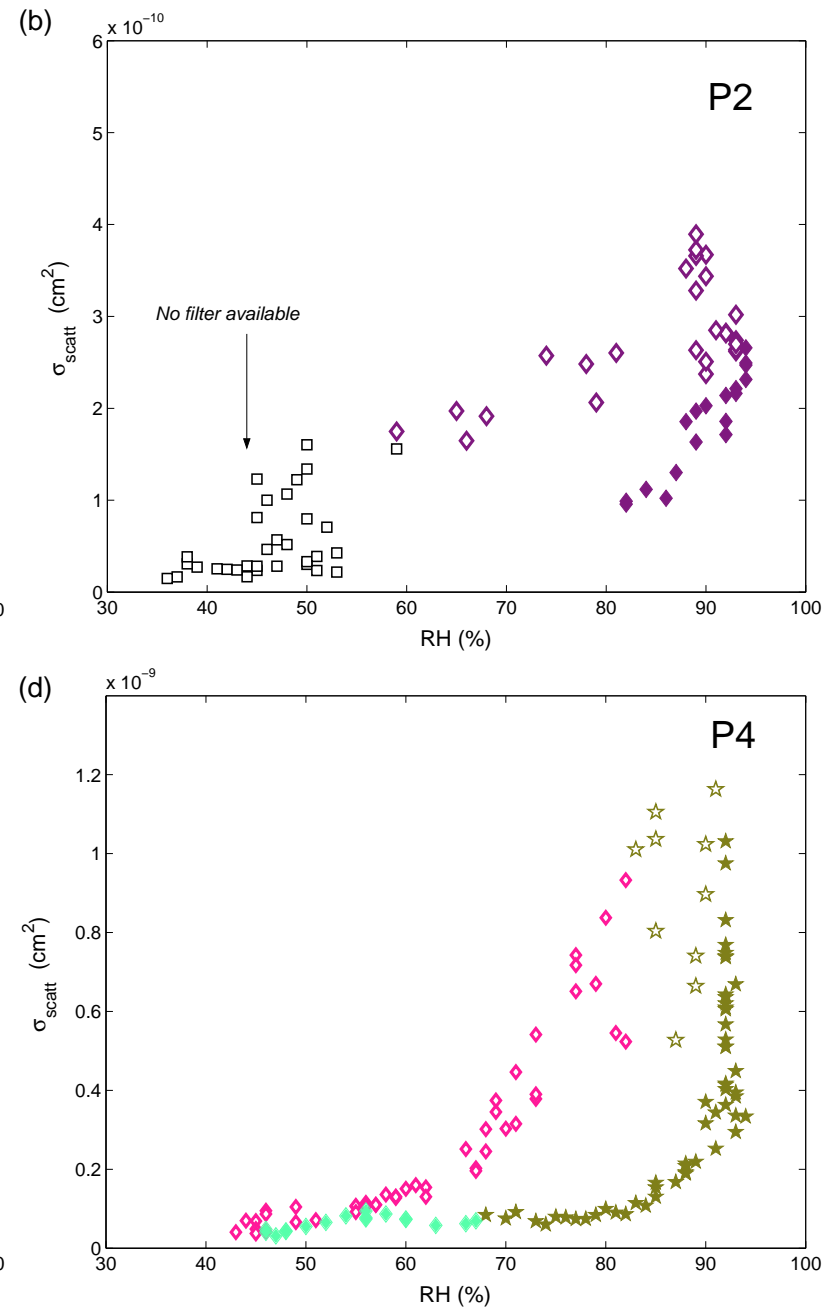

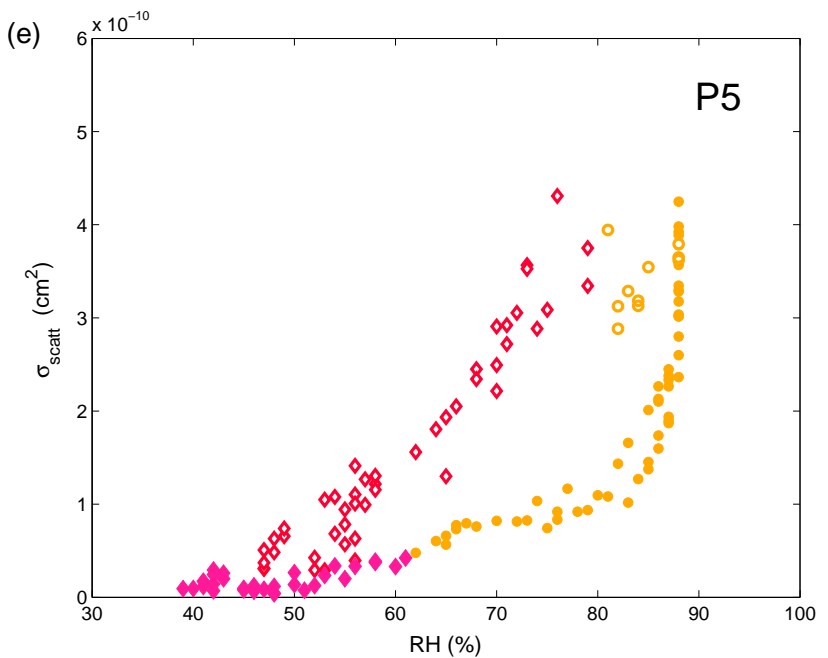

Fig. 2. Aerosol scattering cross section $\sigma_{\text {scatt }}$ as a function of $R H$ for the time periods P1, P2, P3, P4, and P5. Filled (open) symbols indicate that $R H$ increases (decreases) continuously during the time evolution of the sampling. The colours correspond to the different sampling chemical filters (see Sect. 4.1). Circle, diamond and star symbols respectively indicate a salt mixture of Type 1, Type 2 and Type 3, according to ISORROPIA results (see Sect. 4.2.2). Note the change of the ordinate scale for P4. 
Table 1. Deliquescence points $D R H$ and crystallization points $C R H$ of pure soluble salts at $298 \mathrm{~K}\left({ }^{\mathrm{a}}\right.$ Tang and Munkelwitz, 1994; ${ }^{\mathrm{b}}$ Dougle et al., 1998; ${ }^{c}$ McMurry and Stolzenburg, 1989).

\begin{tabular}{cccccccc}
\hline & $\mathrm{NH}_{4} \mathrm{HSO}_{4}^{\mathrm{a}}$ & $\mathrm{NH}_{4} \mathrm{NO}_{3}^{\mathrm{b}}$ & $\left(\mathrm{NH}_{4}\right)_{3} \mathrm{H}_{\left(\mathrm{SO}_{4}\right)_{2}^{\mathrm{a}}}$ & $\mathrm{NaNO}_{3}^{\mathrm{a}}$ & $\mathrm{NaCl}^{c}$ & $\left(\mathrm{NH}_{4}\right)_{2} \mathrm{SO}_{4}^{\mathrm{a}}$ & $\mathrm{Na}_{2} \mathrm{SO}_{4}^{\mathrm{a}}$ \\
\hline$D R H(\%)$ & 40 & 60 & 69 & 74.5 & 76.8 & 80 & 84 \\
$C R H(\%)$ & 20 & - & 45 & 30 & 40 & 40 & 60 \\
\hline
\end{tabular}

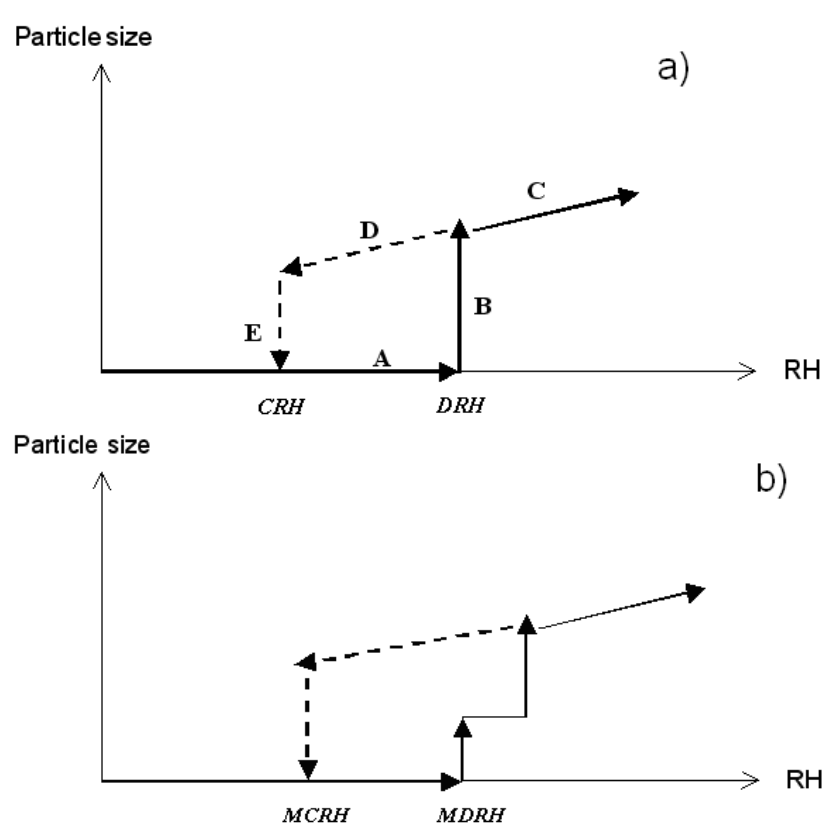

Fig. 3. Diagrams exhibiting deliquescence processes with a hysteresis phenomenon (a) for a pure deliquescent salt and (b) for a mixture of deliquescent salts. Arrows indicate the direction of $R H$ variation.

reported that all of the measured size increases are attributed to water uptake by inorganic species (Waggoner et al., 1983; Malm and Day, 2001). Other authors also report that the extent to which organics enhance or inhibit water uptake depend on the inorganic salts and the fraction of organic material present in the aerosol particle (Cruz and Pandis, 2000).

Another difficulty is that $D R H$ and $C R H$ values depend as much on the chemical composition and on the size of the particles, as on their mixture state (internal/external) and their mixing ratios (Berg et al., 1998; McInnes et al., 1998; Baltensperger et al., 2002). They also vary with the ambient temperature $(T)$, with a decrease of $D R H$ values when $T$ increases (Stelson and Seinfeld, 1982; Tang and Munkelwitz, 1993; Tabazadeh and Toon, 1998). Such a variation is given, at the first order (Tang and Munkelwitz, 1993; Seinfeld and
Pandis, 1998) by:

$$
\left|\frac{\Delta D R H}{D R H}\right|=n \frac{\Delta H_{S}}{R T} \frac{\Delta T}{T}
$$

where $R$ is the perfect gas constant, $\Delta H_{S}$ the solution enthalpy and $n$ the solubility of the aerosol salt.

For the whole period under study, the temperature ( $T$ ) presents a maximum of variation $\Delta T \sim 10^{\circ} \mathrm{C}$ during the diurnal cycle that leads to a $\triangle D R H / R H \sim 3 \%$ for $\mathrm{NH}_{4} \mathrm{NO}_{3}\left(\Delta H_{S} \sim 16.27 \mathrm{~kJ} \mathrm{~mol}^{-1}\right.$ and $n \sim 0.475$ at $\left.298 \mathrm{~K}\right)$ and only $0.3 \%$ for $\left(\mathrm{NH}_{4}\right)_{2} \mathrm{SO}_{4}\left(\Delta H_{S} \sim 6.32 \mathrm{~kJ} \cdot \mathrm{mol}^{-1}\right.$ and $\mathrm{n}$ $\sim 0.104$ at $298 \mathrm{~K})$. Among the four salts which possibly compose our aerosols (see Sect. 4.2.1), only those $\Delta H_{S}$ values of $\mathrm{NH}_{4} \mathrm{NO}_{3}$ and $\left(\mathrm{NH}_{4}\right)_{2} \mathrm{SO}_{4}$ have been found in the literature (Seinfeld and Pandis, 1998). According to such $\triangle D R H / R H$ values, the temperature variations observed here should not have a noticeable influence on the $D R H$ values of the aerosols.

The $D R H$ of a mixed-salt is not necessarily a unique value. Both theoretical and experimental works show that the first deliquescence of a mixture occurs at an $R H$ value lower than the minimum $D R H$ for each salt, taken separately (Tang, 1980b; Spann and Richardson, 1985; Tang and Munkelwitz, 1993; Potukuchi and Wexler, 1995a, 1995b). Figure 3b illustrates the case of a mixed-salt particle deliquescence, where two steps in the phase-change of the aerosol water content are observed when $R H$ increases. The first abrupt increase in the particle size is a result of a phase change from a solid crystal to a heterogeneous droplet, still containing a solid core. The second abrupt increase in particle size occurs when the particle becomes a homogeneous droplet resulting from the dissolution of the droplet's solid core. The minimum $D R H$ of the salts mixture is known as the Mutual Deliquescence Relative Humidity $(M D R H)$ and the crystallization point of the mixed salts is accordingly noted MCRH. A deliquescence process as previously described seems to be observed in the $\sigma_{\text {scatt }}(R H)$ data (Fig. 2), particularly for P4 and P5, with likely $M D R H$ values close to $50-60 \%$. However, at this stage of the data interpretation, we must remain prudent as it is possible that the aerosol chemical composition may have changed between the increasing and the decreasing part of the $R H$ cycle.

Wexler and Seinfeld (1991) proposed a formula to estimate $M D R H$ values for multiple salt solutions, depending on the ambient temperature, the molarity of each salt 
Table 2. Mutual deliquescence points $M D R H$ of mixed salts at 298 K (Potukuchi and Wexler, 1995a, 1995b).

\begin{tabular}{lc}
\hline Salts mixture & MDRH (\%) \\
\hline$\left(\mathrm{NH}_{4}\right)_{2} \mathrm{SO}_{4}, \mathrm{NH}_{4} \mathrm{NO}_{3}$ & 60 \\
$\left(\mathrm{NH}_{4}\right)_{2} \mathrm{SO}_{4}, \mathrm{NH}_{4} \mathrm{NO}_{3}, \mathrm{Na}_{2} \mathrm{SO}_{4}, \mathrm{NH}_{4} \mathrm{Cl}$ & 50 \\
$\left(\mathrm{NH}_{4}\right)_{3} \mathrm{H}\left(\mathrm{SO}_{4}\right)_{2}, \mathrm{Na}_{2} \mathrm{SO}_{4},\left(\mathrm{NH}_{4}\right)_{2} \mathrm{SO}_{4}$ & 68 \\
$\left(\mathrm{NH}_{4}\right)_{3} \mathrm{H}\left(\mathrm{SO}_{4}\right)_{2},\left(\mathrm{NH}_{4}\right)_{2} \mathrm{SO}_{4}$ & 68 \\
\hline
\end{tabular}

and its fusion latent heat from a saturated solution and the molar mass of the water. Results clearly show that mixtures composed of completely different components under the same thermodynamic conditions can have very close $M D R H$ values. For example at $303 \mathrm{~K}, \mathrm{NH}_{4} \mathrm{NO}_{3}+\left(\mathrm{NH}_{4}\right)_{2} \mathrm{SO}_{4}$ present a $M D R H \sim 60 \%$ and under the same conditions, $\mathrm{NaNO}_{3}+\mathrm{NaCl}$ presents a $M D R H \sim 68 \%$ and $\mathrm{NaNO}_{3}+\mathrm{NH}_{4} \mathrm{Cl}$ a $M D R H \sim 60 \%$. Table 2 presents $M D R H$ values for some salt-mixtures at $298 \mathrm{~K}$. To our knowledge, little information is available in literature about the $\mathrm{MCRH}$ of mixed salts.

The $\sigma_{\text {scatt }}(R H)$ response when $R H$ increases and then decreases are significantly different for the P4 and P5 periods. Such observations may support the existence of a hysteresis phenomenon. Moreover, the $M D R H$ values here do not significantly change with the temperature during the $R H$ cycle and thus the temperature variation should not impact on the hysteresis phenomenon. For P2, due to the lack of data between $R H \sim 55 \%$ and $R H \sim 80 \%$ when $R H$ increases, it is difficult to draw any conclusions. However, according to the deliquescence process described above, the $C R H$ should reach the dry state of the cycle close to $R H \sim 50 \%$.

\subsection{The $R H$ effect on the aerosol size distribution}

\subsubsection{Number size distribution}

The mean characteristics of the aerosol number distribution $\rho_{N}(r)$, for the whole period under study, are summarized in Table 3 with the associated temporal variability in brackets and the uncertainties in parenthesis (both explained in the form of standard deviation). The uncertainties due to the retrieval procedure have been assessed using a Monte Carlo approach (Chazette et al., 2005).

Given the $R H$ diurnal cycle, certain parameters of $\rho_{N}(r)$ may evolve significantly with time if the aerosol is hygroscopic. The time evolution of the modal radius $r_{N 1}$ (nucleation mode) presented no variation with $R H$. This mode can thus be considered as hydrophobic. This could be chemistry or size effects as these are the particles that will not pick up water because of the curvature term in the Kohler equation (Seinfeld and Pandis, 1998). The time evolution of the second modal radius $r_{N 2}$ (accumulation mode), considering the uncertainties of $0.02 \mu \mathrm{m}$ (Table 3), is plotted in Fig. 4 together with $R H$ (scaled by 1000). The $r_{N 2}$ values display ev-

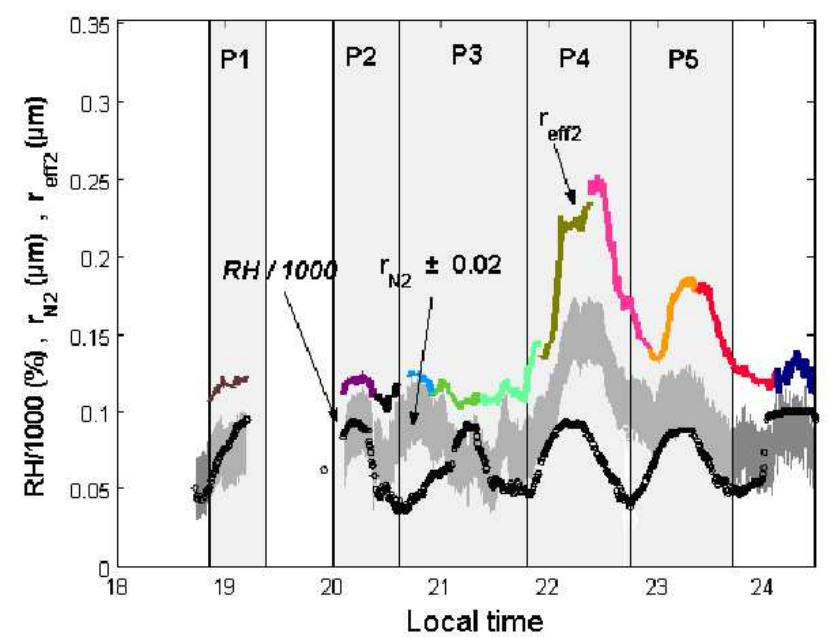

Fig. 4. Time evolution of the modal radius $r_{N 2}$ (grey areas represent the standard deviation around the mean value of $r_{N 2}$ ), the effective radius $r_{\text {eff } 2}$ and $R H / 1000$. The colours correspond to the different sampling chemical filters (see Sect. 4.1).

ident $R H$ effects, as already observed for $\sigma_{\text {scatt }}(R H)$. However, it is difficult to interpret the $r_{N 2}(R H)$ evolution, particularly for P3, because it does not at all follow the variation of $R H$. For this $\mathrm{P} 3$ period, the $\sigma_{\text {scatt }}$ values, which depend on both $r_{N 2}$ and $\sigma_{N 2}$, are weakly but clearly correlated with $R H$ (Fig. 1). A more appropriate radius parameter, which takes into account both of these size distribution parameters, is the effective radius $r_{\text {eff2 }}$ (Chazette et al., 1995; Lenoble, 1993):

$r_{\mathrm{eff} 2}=r_{N 2} \exp \left(2.5 \cdot \ln ^{2} \sigma_{N 2}\right)$

For the periods $\mathrm{P} 1$ and $\mathrm{P} 3, r_{\text {eff } 2}$ shows a not significant variability with $R H$, in agreement with $\sigma_{\text {scatt }}(R H)$. The effect of $R H$ on $r_{\text {eff } 2}$ is well highlighted for P4 and P5, with the same observed trends as for $\mathrm{r}_{N 2}(R H)$ and $\sigma_{\text {scatt }}(R H)$. The similarity of behaviour between $\sigma_{\text {scatt }}$ and $r_{N 2}$ could still be an artefact due to a variation over time of either the aerosol chemical components or the occupation rate $x_{2}$. However, the occupation rate $x_{N 2}$ stays roughly constant with a standard deviation of $10 \%$ which leads to an effect on $\sigma_{\text {scatt }}$ lower than $15 \%$ and is thus insufficient in explaining the existence of a hysteresis pattern (Figs. 2d, e). The partition of hygroscopic components inside each mode is thus important to establish. The evolution of the coarse mode radius $r_{N 3}$ as a function of $R H$ was not performed due to the difficulty to assess precisely this mode from number size distributions. It is nonetheless important to determine if this third mode is also hygroscopic and the knowledge of the mass size distribution of the aerosol chemical compounds would then be helpful. Unfortunately, such measurements were not performed at the Saclay location during this observation period but they were performed in inner Paris between 18 and 21 July 2000. We may nonetheless reasonably suppose that the type of aerosol 
Table 3. Mean number size distribution $\rho_{N}(\mathrm{r})$ retrieved from measurements at Saclay (Chazette et al., 2005) and mean mass size distribution $\rho_{M}(\mathrm{r})$ from measurements in inner Paris. The number size distribution parameters assessed from the mass size distribution are also given. The mean optical contribution of each mode is indicated for $550 \mathrm{~nm}$. The temporal variability is given in brackets and the uncertainties in parenthesis. Both have been calculated as standard deviations.

\begin{tabular}{|c|c|c|c|c|c|c|c|c|}
\hline & $r_{1}(\mu \mathrm{m})$ & $\sigma_{1}$ & $x_{1}(\%)$ & $r_{2}(\mu \mathrm{m})$ & $\sigma_{2}$ & $x_{2}(\%)$ & $r_{3}(\mu \mathrm{m})$ & $\sigma_{3}$ \\
\hline Measured $\rho_{N}(r)$ & $\begin{array}{l}0.03 \\
\{0.01\} \\
(0.01)\end{array}$ & $\begin{array}{l}1.4 \\
\{0.2\} \\
(0.01)\end{array}$ & $\begin{array}{l}87.94 \\
\{9\} \\
(3)\end{array}$ & $\begin{array}{l}0.09 \\
\{0.02\} \\
(0.015)\end{array}$ & $\begin{array}{l}1.5 \\
\{0.1\} \\
(0.02)\end{array}$ & $\begin{array}{l}12 \\
\{5\} \\
(3)\end{array}$ & $\begin{array}{l}0.45 \\
\{0.03\} \\
(0.1)\end{array}$ & $\begin{array}{l}1.2 \\
\{0.4\} \\
(0.02)\end{array}$ \\
\hline Measured $\rho_{M}(r)$ & - & - & - & $\begin{array}{l}0.22 \\
(0.02)\end{array}$ & $\begin{array}{l}1.5 \\
(0.1)\end{array}$ & $\begin{array}{l}69 \\
(5)\end{array}$ & $\begin{array}{l}3.5 \\
(0.02)\end{array}$ & $\begin{array}{l}1.3 \\
(0.1)\end{array}$ \\
\hline $\begin{array}{l}\text { Assessed } \rho^{\prime}{ }_{N}(r) \\
\text { from } \rho_{M}(r)\end{array}$ & - & - & - & $\begin{array}{l}0.13 \\
(0.05)\end{array}$ & $\begin{array}{l}1.5 \\
(0.1)\end{array}$ & $\begin{array}{l}53 \\
(7)\end{array}$ & $\begin{array}{l}2.5 \\
(0.06)\end{array}$ & $\begin{array}{l}1.3 \\
(0.1)\end{array}$ \\
\hline $\begin{array}{l}\text { Contribution } \\
\text { to } \sigma_{\text {scatt }}\end{array}$ & & $\sim 4 \%$ & & & $\sim 77 \%$ & & & \\
\hline
\end{tabular}

emission in inner Paris area is the same than around Saclay since the main aerosol source is the automobile traffic (Menut et al., 2000).

\subsubsection{Mass size distribution}

The aerosol sampled in Paris by the DEKATI instrument provided mass size distributions of the WS fraction, noted $\rho_{M}$ (Fig. 5a), and the elementary species, noted $\rho_{M, E}$ (Fig. 5b), using respectively ion chromatography and X-ray fluorescence analysis.

The nucleation mode, previously identified in the number size distribution $\rho_{N}(r)$, is poorly constrained with mass concentration measurements because this mode contributes very little to the total aerosol mass. Thus, the two modes well identified by $\rho_{M}$ and $\rho_{M, E}$ correspond to the accumulation mode with a modal radius $r_{M 2} \sim 0.22 \mu \mathrm{m}$ and to the coarse mode with a modal radius $r_{M 3} \sim 3.5 \mu \mathrm{m}$.

The main chemical composition of each mode is determined by the combination of both distributions. When the common components of Figs. 5a and b are compared, there are agreements between molar concentrations of $\mathrm{SO}_{4}^{2-}$ and $\mathrm{S}$ for the mode close to $r_{M 2} \sim 0.22 \mu \mathrm{m}$, and between molar concentrations of $\mathrm{Na}^{+}$and $\mathrm{Na}$ for the mode close to $r_{M 3} \sim 3.5 \mu \mathrm{m}$. Such results indicate that sulphur and sodium exist essentially in respective ionic forms as $\mathrm{SO}_{4}^{2-}$ and $\mathrm{Na}^{+}$. As for the $\mathrm{Cl}, \mathrm{Mg}$ and $\mathrm{K}$ components, present in the coarse mode close to $r_{M 3} \sim 3.5 \mu \mathrm{m}$, they are essentially in solid forms. Note that these three components represent less than $2 \%$ of the aerosol total mass. The mode close to $r_{M 2} \sim 0.22 \mu \mathrm{m}$ thus contains mainly soluble components while the mode close to $r_{M 3} \sim 3.5 \mu \mathrm{m}$ contains principally insoluble components. Traffic emission is more likely to be in the nucleation and accumulation modes. Nevertheless, cars inject also in the atmosphere particles by friction on surface in the coarse mode. Using the same approach than Bates et al. (2004), the dust mass concentration in the coarse mode has been found $\sim 3.9 \mu \mathrm{g} \mathrm{m}^{-3}$. Nitrate concentration observed in the coarse mode may be due to reaction of calcium carbonate with nitric acid onto mineral dust particles.

It is important to ascertain that the two modes highlighted by the mass size distributions $\rho_{M}(r)$ and $\rho_{M, E}(r)$ correspond to the last two modes of the number size distribution $\rho_{N}(r)$. For lognormal distributions, there are well defined relationships between the number and the mass modal radii in one hand, and between their fractional number concentrations in the other hand:

$r_{N}=r_{M} \exp \left(-3 \log ^{2}\left(\sigma_{M}\right)\right)$

$x_{N}=\left(3 / 4 \pi d_{\text {dry }}\right) x_{M} 10^{2} r_{N^{\prime}}^{-3} \exp \left(-9 \log ^{2}\left(\sigma_{N}\right) / 2\right)$

where $d_{\text {dry }}\left(\mathrm{g} . \mathrm{cm}^{3}\right)$ is the dry particle density. Subscripts $M$ and $N$ respectively correspond to mass and number distributions. For the same mode, standard deviations $\sigma_{N}$ and $\sigma_{M}$ should have the same value. An independant number size distribution, noted $\rho_{N}^{\prime}(r)$, can then be assessed from the characteristics of $\rho_{M}(r)$. According to the previous chemical composition given for each mode, $d_{\text {dry }}$ can be assumed to be equal, for the mode $r_{M 2} \sim 0.22 \mu \mathrm{m}$ to the WS fraction $d_{\mathrm{WS}} \sim .7 \mathrm{g.cm}{ }^{-3}$ (Sloane, 1984; Boucher and Anderson, 1995) and for the mode $r_{M 3} \sim 3.5 \mu \mathrm{m}$ to the residual particles (including dust particles) $d_{\text {dust }} \sim .3 \mathrm{~g} . \mathrm{cm}^{-3}$ (Patterson and Gillette, 1977). The mean characteristics of $\rho_{M}(r)$ and the corresponding $\rho_{N}^{\prime}(r)$ are given in Table 3.

The first mode $\left(r_{N 2^{\prime}} \sim 0.13 \pm 0.05 \mu \mathrm{m}\right)$ of this number distribution derived from $\rho_{M}(r)$ agrees relatively well with the second mode $\left(r_{N 2} \sim 0.09 \pm 0.02 \mu \mathrm{m}\right)$ of $\rho_{N}(r)$. This mode, containing mainly soluble components, contributes the most to the hygroscopic properties of the aerosols. According to Mie theory calculations, it is also the most optically efficient, 

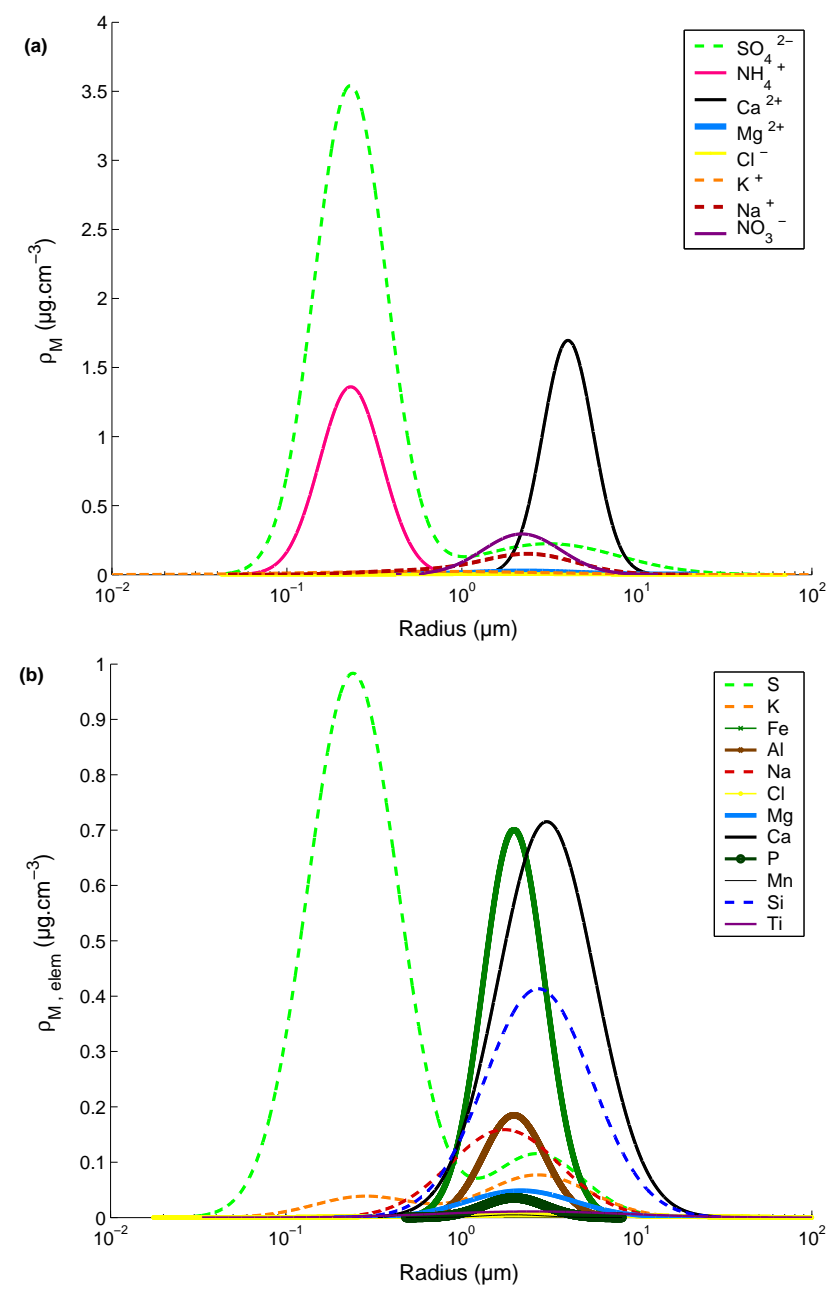

Fig. 5. Mass size distributions of (a) water soluble fraction obtained by chromatography analysis and (b) elementary compounds obtained by X-ray fluorescence analysis, retrieved from the filters sampled in Paris (between 18 and 21 July 2000).

with about $77 \%$ of the total aerosol scattering efficiency (Table 3). Organic content may also have an effect on the hydroscopic properties of aerosols. The OC content for the two modes is not so different $\left(\sim 2 \mu \mathrm{g} \mathrm{m}^{-3}\right.$ for the accumulation mode and $\sim 1 \mu \mathrm{g} \mathrm{m}^{-3}$ for the coarse mode). If the OC is hydrophilic, the coarse mode may influence the aerosol scattering cross section against $R H$.

The discrepancy observed in Table 3 between $r_{N 3}$ and $r_{N 3^{\prime}}$ is likely due to the inherent difficulty in measuring the particle number size distribution in the coarse mode which is better characterized using mass measurements. We can thus suppose that the correct modal radius of the third mode is closer to $2.5 \mu \mathrm{m}$ rather than $0.45 \mu \mathrm{m}$. Furthermore, this mode has been found to contain mainly insoluble species. In the next sections, we will thus focus our study on the accumulation mode $\left(r_{N 2} \sim 0.09 \mu \mathrm{m}\right)$.

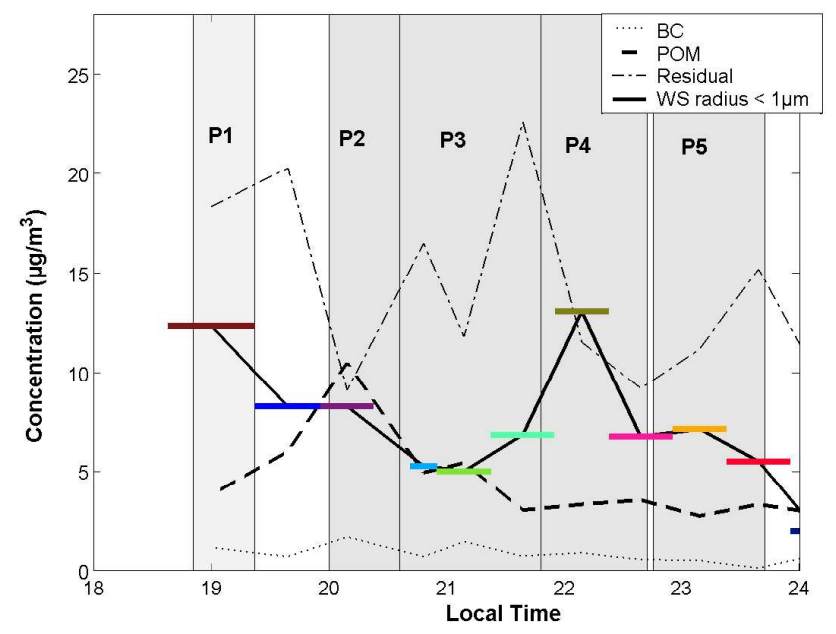

Fig. 6. Time evolution of $\mathrm{BC}, \mathrm{POM}, \mathrm{WS}_{<1 \mu \mathrm{m}}$, and residuals (including dusts) concentrations measured at Saclay between 18 and 24 July 2000. Horizontal coloured bars identify the sampling filters (see Sect. 4.1). The grey areas highlight the 5 time periods (P1, P2, P3, P4, and P5).

\section{Temporal evolution of the aerosol chemical composi- tion}

\subsection{Aerosol sampling}

Ten aerosol samplings were realized at Saclay, for carbonaceous and water-soluble analysis, with a night and daytime alternation when possible. The length of sampling times ranged from 6 to $18 \mathrm{~h}$. Results show that on the average the aerosol is composed of $35 \%$ of WS, $15 \%$ of POM, $3 \%$ of $\mathrm{BC}$, and $47 \%$ of residual components including the dust fraction. Given the size cut of the filters, the WS fraction can be divided into two categories: particles with radius $<1 \mu \mathrm{m}$ (WS $<1 \mu \mathrm{m})$ and particles with radius $>1 \mu \mathrm{m}\left(\mathrm{WS}_{<1 \mu \mathrm{m}}\right)$. The coarse mode contains $\sim 30 \%$ of WS, which must especially found in the form of calcium nitrate. We will hereafter focus on $\mathrm{WS}_{<1 \mu \mathrm{m}}$ which includes the accumulation mode. According to these ten aerosol samples from Saclay, the preponderant components in $\mathrm{WS}_{<1 \mu \mathrm{m}}$ are ion sulphate $\mathrm{SO}_{4}^{2-}$ with a mean relative proportion of $\sim 68 \%$, followed by ammonium $\mathrm{NH}_{4}^{+}$with $\sim 21 \%$ and nitrate $\mathrm{NO}_{3}^{-}$with $\sim 8 \%$. This repartition of $\mathrm{WS}_{<1 \mu \mathrm{m}}$ species is quite similar to the one obtained from Paris measurements (see Fig. 5).

The time series of $\mathrm{WS}_{<1 \mu \mathrm{m}}, \mathrm{BC}$ and POM mass concentrations are shown in Fig. 6 and the the relative repartition of the five main components of $\mathrm{WS}_{<1 \mu \mathrm{m}}$ from Saclay $\left(\mathrm{SO}_{4}^{2-}, \mathrm{NH}_{4}^{+}, \mathrm{NO}_{3}^{-}, \mathrm{Na}^{+}\right.$, and $\left.\mathrm{Cl}^{-}\right)$is displayed in Fig. 7 . In the latter, a noticeable diurnal cycle of $\mathrm{NO}_{3}^{-}$is observed with a higher relative concentration at night than during the day. This process results from the destruction of $\mathrm{NO}_{3}^{-}$by photo-dissociation during the day, whereas it is produced during the night from ozone and nitrogen dioxide molecules. 


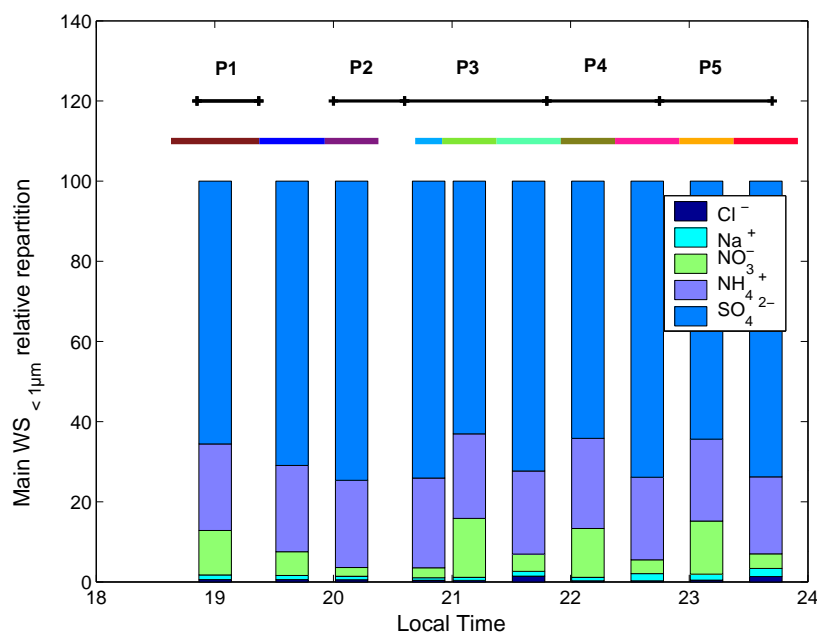

Fig. 7. Time evolution of the relative mass concentration of the main $\mathrm{WS}_{<1 \mu \mathrm{m}}$ ionic compounds.

Nonetheless it still remains to be seen whether this has an impact on the aerosol hygroscopic character.

Among the five time periods, the strongest $\mathrm{WS}_{<1 \mu \mathrm{m}}$ concentrations are observed during P1 and P4. Their aerosol hygroscopic behaviours are nevertheless very different with a clear high hygroscopicity for $\mathrm{P} 4$. We note that $\mathrm{P} 1$ has a slightly greater $\mathrm{POM}$ organic fraction than $\mathrm{P} 4$ and it is possible that POM inhibited the aerosol hygroscopicity during P1 as mentioned by various authors (e.g. Cruz and Pandis, 1998; Kleindienst et al., 1999). However, the latter assumption must be tempered by the lack of data during daytime of 19 July. As for P3 and P5, quasi-similar concentrations of WS are observed, although the mean concentration of POM is twice as important for P3. Considering the high hygroscopic properties of $\mathrm{P} 5$, this may also support the interpretation that POM inhibits the aerosol hygroscopic properties. However, in our case, this interpretation is not fully satisfactory. P2 indeed presents the most significant quantity of POM but the aerosol seem to preserve a pronounced hygroscopic character, despite a weaker $\mathrm{WS}_{<1 \mu \mathrm{m}}$ concentration when compared to P1. These contradictory observations, concerning the presence of organic compounds, echo the works of different authors previously cited and demonstrate the difficulty to draw conclusions on the aerosol hygroscopic character solely based on the chemical data analysis as presented here.

An analysis of the air masses origins has been conducted for the 5 time periods (Fig. 8), using the NOAA HYSPLIT4 Model (Draxler and Hess, 1998), with the aim of better comprehending the obtained data. The air masses come from northwest for P1 and P3, with a larger spreading for the latter. The weak hygroscopic character of the aerosols for both cases, observed in Figs. $2 \mathrm{a}$ and $\mathrm{c}$ are similar. The air masses passed through the industrialized regions of Leeds, Sheffield and London (England) and are, upon arrival over Paris, cer-

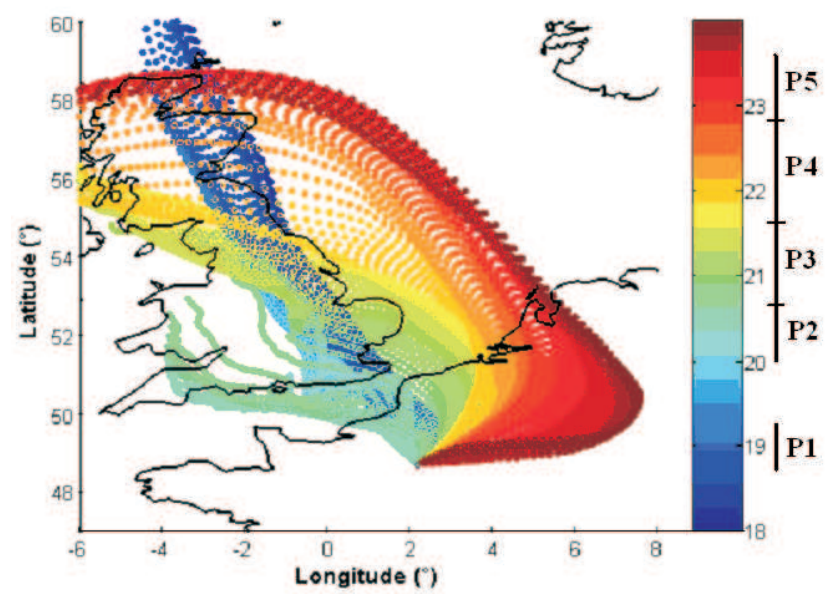

Fig. 8. Retro-trajectories of air masses arriving over the Paris area for the period between 18 and 23 July 2000. The color scale represents the temporal evolution with the five time periods.

tainly already loaded with aged hydrophobic pollution particles. An aerosol optical properties study from airborne lidar measurements (Chazette et al., 2005) confirms the weak hygroscopicity of the aerosols present in the Paris area during daytime of 19 July 2000 (period P1). For P2, the incoming air mass is a mix between northwest (at the beginning of the period) and west (at the end) airflows which are probably already polluted, but with a more urban pollution component (London).

The situation of $\mathrm{P} 4$ contrasts totally with the previous cases. The air masses come from the Northeast, after travelling over the Northerly part of the Great Britain, the North Sea and the Benelux. We may thus expect a different aerosol hygroscopic behaviour given the difference of sources and the fact that the particles arriving over the Paris area are certainly less aged. For P5, the air masses arrive from east and northeast. They originate from the North Sea and have passed over the Benelux and western Germany. A hygroscopic behaviour similar to the one observed during $\mathrm{P} 4$ should thus be expected, as confirmed by the Figs. $2 \mathrm{~d}$ and e.

\subsection{Modeling approach}

We have used ISORROPIA, a thermodynamic model which predicts the phase state (gas, liquid, solid) of inorganic atmospheric aerosol components in equilibrium with gas phase precursors (Nenes et al., 1998). It models the sodiumammonium-chloride-sulphate-nitrate-water aerosol system. On one hand, it proposes the possible chemical forms of the salts within the aerosol solid phase in accordance with $R H$ values. On the other hand, it calculates the aerosol water mass content $\mathrm{m}_{\mathrm{H}_{2} \mathrm{O}}$ as a function of increasing $R H$ and assesses the corresponding $M D R H$ values. The main goal of this section is to compare $m_{\mathrm{H}_{2} \mathrm{O}}(R H)$ to the measured 


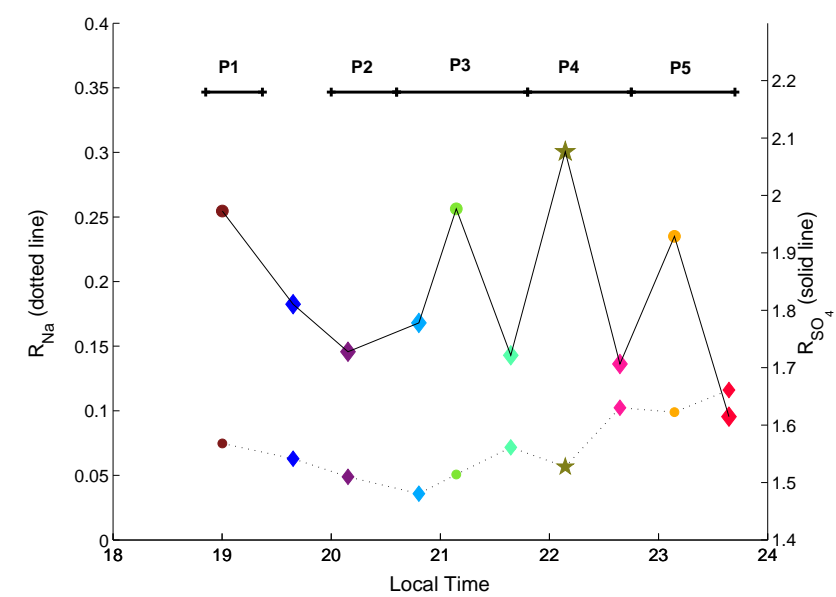

Fig. 9. Time evolution of $\mathrm{R}_{\mathrm{SO}_{4}}$ and $\mathrm{R}_{\mathrm{Na}}$. The colours identify the sampling filters (see Sect. 4.1). Circle, diamond and star symbols respectively indicate the Type 1 , Type 2 , and Type 3 pattern of the salt mixture (see Sect. 4.2.2).

$\sigma_{\text {scatt }}(R H)$ and $r_{N 2}(R H)$, even if this is only possible for the increasing $R H$ part of the cycle.

In ISORROPIA, the aerosol particles are assumed to be internally mixed. The model solves a "reverse" problem in which the known quantities are the temperature, $R H$ and the aerosol ionic concentrations of $\mathrm{SO}_{4}^{2-}, \mathrm{NH}_{4}^{+}, \mathrm{NO}_{3}^{-}, \mathrm{Na}^{+}$, and $\mathrm{Cl}^{-}$. The number of viable species is determined by the relative amount of each species and the ambient $\mathrm{RH}$. Possible species in solid phase are: $\left(\mathrm{NH}_{4}\right)_{2} \mathrm{SO}_{4}, \mathrm{NH}_{4} \mathrm{HSO}_{4}$, $\left(\mathrm{NH}_{4}\right)_{3} \mathrm{H}\left(\mathrm{SO}_{4}\right)_{2}, \mathrm{NH}_{4} \mathrm{NO}_{3}, \mathrm{NH}_{4} \mathrm{Cl}, \mathrm{NaCl}, \mathrm{NaNO}_{3}, \mathrm{NaHSO}_{4}$ and $\mathrm{Na}_{2} \mathrm{SO}_{4}$ (Nenes et al., 1998).

\subsubsection{Identification of salts}

Depending on the amount of $\mathrm{NH}_{4}^{+}$and $\mathrm{Na}^{+}$, the $\mathrm{SO}_{4}^{2-}$ can either be completely or partially neutralized. The possible salt mixture present inside the aerosol is thus characterized using two ionic ratios defined by:

$\mathrm{R}_{\mathrm{SO}_{4}}=\frac{\left[\mathrm{Na}^{+}\right]+\left[\mathrm{NH}_{4}^{+}\right]}{\left[\mathrm{SO}_{4}^{2-}\right]}$

$\mathrm{R}_{\mathrm{Na}}=\frac{\left[\mathrm{Na}^{+}\right]}{\left[\mathrm{SO}_{4}^{2-}\right]}$

$\mathrm{R}_{\mathrm{SO}_{4}}$ is known as the sulphate ratio, while $\mathrm{R}_{\mathrm{Na}}$ is known as the sodium ratio. The concentrations are defined in molar units. Different cases may occur, according to the $\mathrm{R}_{\mathrm{SO}_{4}}$ and $\mathrm{R}_{\mathrm{Na}}$ values:

1. if $\mathrm{R}_{\mathrm{SO} 4}<1$, the particle aerosols belong to the "Sulphate rich with free acid" case where there is a high quantity of $\mathrm{SO}_{4}^{2-}$, part of which is in a free sulphuric acid $\mathrm{H}_{2} \mathrm{SO}_{4}$ form.

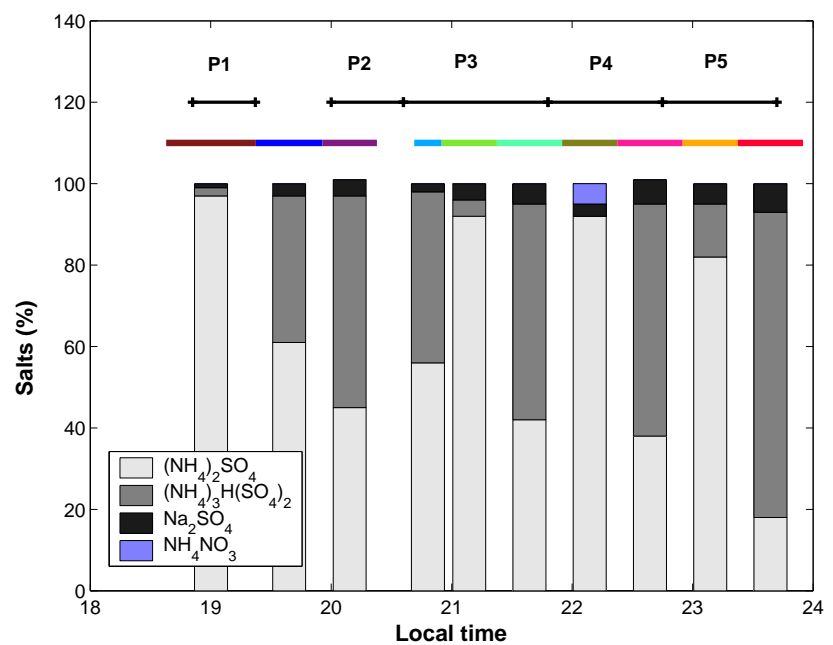

Fig. 10. Time evolution of the relative composition of the formed salts. Coloured horizontal bars identify the sampling filters (see Sect. 4.1).

2. if $1<\mathrm{RSO}_{4}<2$, the particle aerosols belong to the "Sulphate rich but no free acid" case where there is enough $\mathrm{NH}_{4}^{+}$and $\mathrm{Na}^{+}$to partially neutralize $\mathrm{SO}_{4}^{2-}$. In addition of $\mathrm{Na}_{2} \mathrm{SO}_{4}$, a mixture of $\left(\mathrm{NH}_{4}\right)_{2} \mathrm{SO}_{4}$ and $\left(\mathrm{NH}_{4}\right)_{3} \mathrm{H}\left(\mathrm{SO}_{4}\right)_{2}$ exists, the ratio of which is determined by the thermodynamic equilibrium.

3. if $\mathrm{R}_{\mathrm{SO}_{4}} \geq 2$ and $\mathrm{R}_{\mathrm{Na}} \leq 2$, the particle aerosols belong to the "Sulphate poor and Sodium poor" case where there is enough $\mathrm{NH}_{4}^{+}$and $\mathrm{Na}^{+}$to fully neutralize $\mathrm{SO}_{4}^{2-}$, but $\mathrm{Na}^{+}$concentration is not sufficient to neutralize $\mathrm{SO}_{4}^{2-}$ by itself. The excess of $\mathrm{NH}_{4}^{+}$can react with other species like $\mathrm{NO}_{3}^{-}$and $\mathrm{Cl}^{-}$to form other salts.

4. if $\mathrm{R}_{\mathrm{SO}_{4}} \geq 2$ and $\mathrm{R}_{\mathrm{Na}} \geq 2$, the particle aerosols belong to the "Sulphate poor and Sodium rich" case where there is enough $\mathrm{Na}^{+}$to fully neutralize $\mathrm{SO}_{4}^{2-}$. The $\mathrm{NH}_{4}^{+}$and the excess of $\mathrm{Na}^{+}$can react with other gaseous species to form salts, while no $\mathrm{NH}_{4} \mathrm{HSO} 4$ nor $\left(\mathrm{NH}_{4}\right)_{3} \mathrm{H}\left(\mathrm{SO}_{4}\right)_{2}$ are formed.

The measurement of $\mathrm{SO}_{4}^{2-}, \mathrm{NH}_{4}^{+}, \mathrm{NO}_{3}^{-}, \mathrm{Na}^{+}$, and $\mathrm{Cl}^{-}$ mass concentrations from the ten aerosol samples leads to the $\mathrm{R}_{\mathrm{SO}_{4}}$ and $\mathrm{R}_{\mathrm{Na}}$ values displayed in Fig. 9. The corresponding modelled salt proportions are shown in Fig. 10. The only sample belonging to the "Sulphate poor and Sodium poor" case is the one close to day 22.3 (green star symbol) which corresponds to the increasing $\mathrm{RH}$ part of the $\mathrm{P} 4$ cycle and is composed of $\left(\mathrm{NH}_{4}\right)_{2} \mathrm{SO}_{4}, \mathrm{Na}_{2} \mathrm{SO}_{4}$, and $\mathrm{NH}_{4} \mathrm{NO}_{3}$. The nine other samples recorded during P1, P2, P3, and P5 correspond to the case "Sulphate rich but no free acid" and contain $\left(\mathrm{NH}_{4}\right)_{2} \mathrm{SO}_{4}, \mathrm{Na}_{2} \mathrm{SO}_{4}$, and $\left(\mathrm{NH}_{4}\right)_{3} \mathrm{H}\left(\mathrm{SO}_{4}\right)_{2}$. No $\mathrm{NH}_{4} \mathrm{HSO} 4$ was formed in these cases because $\mathrm{R}_{\mathrm{SO}_{4}}$ has to be lower than 1.5 to form such a component. $\left(\mathrm{NH}_{4}\right)_{2} \mathrm{SO}_{4}$ is present 


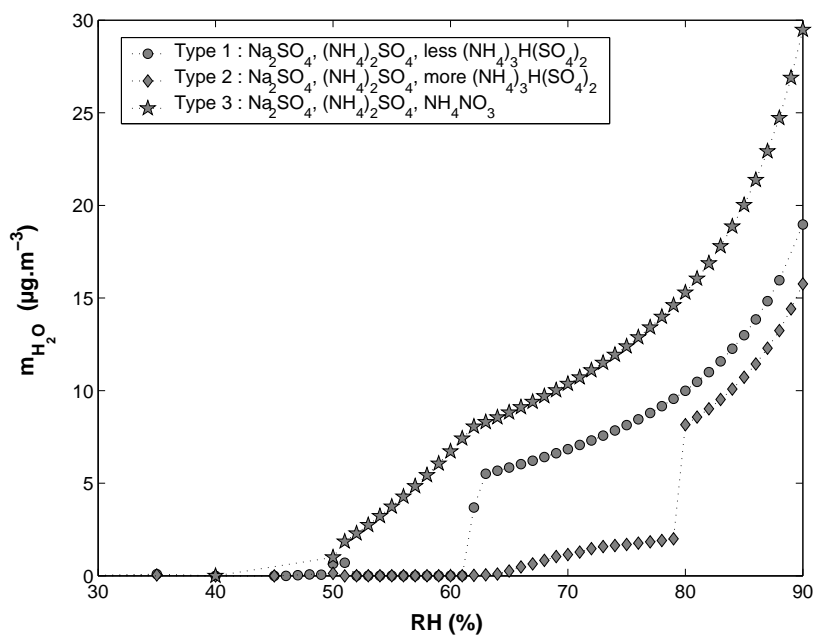

Fig. 11. The three patterns of aerosol water content evolution with $R H$ from the ten filter samples: circles for Type 1, diamonds for Type 2, and stars for Type 3 .

during the entire observation period with a proportion ranging from 18 to $97 \%$ of the total $\mathrm{WS}_{<1 \mu \mathrm{m}}$ mass, while the $\left(\mathrm{NH}_{4}\right)_{3} \mathrm{H}\left(\mathrm{SO}_{4}\right)_{2}$ proportion varies between 0 and $75 \%$. The formation of $\mathrm{NH}_{4} \mathrm{NO}_{3}$ during $\mathrm{P} 4$ comes from an excess, even weak, of $\mathrm{NH}_{4}^{+}$which combines with other ions than $\mathrm{SO}_{4}^{2-}$, such as $\mathrm{NO}_{3}^{-}$.

From this chemical composition approach, it thus seems that the various behaviours of the measured aerosol optical properties with increasing $R H$ could be divided into at least two classes.

\subsubsection{Aerosol mass water content}

The aerosol water mass content $m_{\mathrm{H}_{2} \mathrm{O}}$, as a function of increasing $R H$, has been calculated from ISORROPIA according to the chemical composition of the ten filter samplings. The retrieved behaviours of $m_{\mathrm{H}_{2} \mathrm{O}}(R H)$ can be grouped in three different patterns, hereafter referenced as Type 1, Type 2, and Type 3, as displayed in Fig. 11 (respectively identified with circle, diamond and star symbols). Each period (P1 to P5) includes up to 3 filters and thus different patterns could be encountered. It is obvious that the aerosol chemical composition given by each sampling filter is a mean value of the aerosol chemistry during the sampling time. However, the aerosol chemical composition should not change instantaneously.

The Type 1 pattern concerns the whole $\mathrm{P} 1$ period and the parts of $\mathrm{P} 3$ and $\mathrm{P} 5$ for increasing $R H>60 \%$. The Type 3 pattern concerns the filter sampled during the part of $\mathrm{P} 4$ for increasing $R H>60 \%$ and the beginning of the decreasing leg, the modelled species of which are $\left(\mathrm{NH}_{4}\right)_{2} \mathrm{SO}_{4}, \mathrm{NH}_{4} \mathrm{NO}_{3}$ and $\mathrm{Na}_{2} \mathrm{SO}_{4}$ with no $\left(\mathrm{NH}_{4}\right)_{3} \mathrm{H}\left(\mathrm{SO}_{4}\right)_{2}$. Type 2 applies to $\mathrm{P} 2$ and all the remaining filters of $\mathrm{P} 3, \mathrm{P} 4$ and $\mathrm{P} 5$. In fact, the only meaningful $m_{\mathrm{H}_{2} \mathrm{O}}(R H)$ behaviours of the particles are those for $R H$ values where the particles do react with $R H$, i.e. for the increasing $R H$ part of the cycle beyond the deliquescence point. According to the model, the deliquescence for Type 1 and Type 2 should occur close to $M D R H \sim 60 \%$ and for the Type 3 close to $M D R H \sim 50 \%$. We thus consider that $m_{\mathrm{H}_{2} \mathrm{O}}(R H)$ follows a behaviour of Type 1 for $\mathrm{P} 1, \mathrm{P} 3$, and $\mathrm{P} 5$, of Type 2 for P2 and of Type 3 for P4.

As shown previously, the salts which compose the Type 1 and Type 2 aerosols are the same $\left(\left(\mathrm{NH}_{4}\right)_{2} \mathrm{SO}_{4}\right.$, $\left(\mathrm{NH}_{4}\right)_{3} \mathrm{H}\left(\mathrm{SO}_{4}\right)_{2}$, and $\left.\mathrm{Na}_{2} \mathrm{SO}_{4}\right)$. The main difference is in the growth with $R H$ which is more continuous up to $R H \sim 80 \%$ for Type 2 than for Type 1 . Such a difference could be due to the $\left(\mathrm{NH}_{4}\right)_{3} \mathrm{H}\left(\mathrm{SO}_{4}\right)_{2}$ fraction which is weaker in Type 1 $(<13 \%)$ than in Type $2(>36 \%)$. The difference between the latter patterns and Type 3 is certainly due to the presence of $\mathrm{NH}_{4} \mathrm{NO}_{3}$ and the absence of $\left(\mathrm{NH}_{4}\right)_{3} \mathrm{H}\left(\mathrm{SO}_{4}\right)_{2}$.

Coming back to the $\sigma_{\text {scatt }}(R H)$ characteristics of the Fig. 2, we note that the observed $M D R H$ of P5, close to 50$60 \%$, and that of $\mathrm{P} 4$, close to $40-50 \%$ and less pronounced, seem to be in good agreement respectively with the characteristics of Type 1 and Type 3 .

\section{Parameterisation}

Using a parameterisation approach based on Hänel (1976) model, we will check, in the following sections, the coherence between $m_{\mathrm{H}_{2} O}(R H), \sigma_{\text {scatt }}(R H)$ and $r_{N 2}(R H)$. Since this model is suitable only for continuously increasing $R H$, we will hereafter mainly focus on the increasing $R H$ part of the time cycle. At that stage of the discussion, the hysteresis effect still remains questionable and we shall use these parameterisations to determine if this phenomenon really exists on our data.

\subsection{Growth factors}

\subsubsection{Aerosol scattering growth factor $f_{\text {scatt }}(R H)$}

The growth of aerosol light scattering as a function of increasing RH, noted $f_{\text {scatt }}(R H)$, is defined as the ratio between wet and dry scattering cross sections:

$f_{\text {scatt }}(R H)=\sigma_{\text {scatt }}(R H) / \sigma_{\text {scatt,dry }}$

where $\sigma_{\text {scatt,dry }}$ is the scattering cross-section at $R H<30 \%$. For the present study, we have used $\sigma_{\text {scatt, ref }}$ instead of $\sigma_{\text {scatt,dry }}$, which corresponds to a reference $R H$ value $R H_{\text {ref }}$ since values of $R H \leq 30 \%$ were not available. We chose to use $R H_{\text {ref }} \sim 50-60 \%$, given the available data. These $R H_{\text {ref }}$ values are very close to the $M D R H$ values predicted by ISORROPIA, where the aerosols are considered to be in dry state. Moreover, up to the time when $R H$ reaches these values, one remains generally with the same sampling filter.

Figure 12 shows $f_{\text {scatt }}(R H)$ for $\mathrm{P} 1, \mathrm{P} 3, \mathrm{P} 4$ and $\mathrm{P} 5$. The $f_{\text {scatt }}$ value at $R H=80 \%$ is frequently used in the current 
Table 4. Measured scattering growth $f_{\text {scatt }}(80 \%)$ and scattering growth coefficient $\gamma$ for the present work and from other authors $(*$ the given range corresponds to different sensitivity tests on the size, the chemical form of the aerosol, and the hysteresis presence).

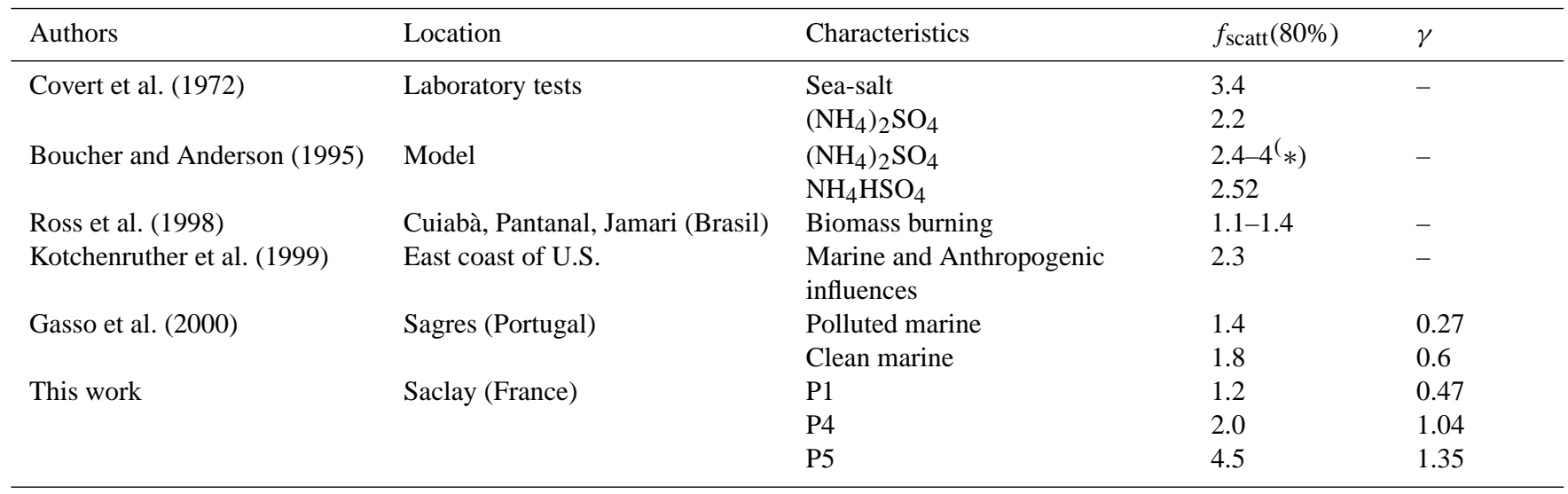

literature (e.g. Covert et al., 1974; Boucher and Anderson, 1995; Ross et al., 1998; Kotchenruther et al., 1999 and Gasso et al., 2000) to appreciate the degree of hygroscopicity of the aerosols. These values are summarized in Table 4 together with those given by other authors. The P2 period has been discarded due to the lack of increasing $R H$ data up to $R H \sim 80 \%$. The values of $f_{\text {scatt }}(80 \%)$ are very sparse and clearly dependant on both the aerosol origin and the particle chemical composition. For P1 and $\mathrm{P} 3, f_{\text {scatt }}(80 \%) \sim 1.1-1.2$ are close to the values found by Ross et al. (1998) and Gasso et al. (2000) for biomass burning and polluted marine aerosols, respectively. For $\mathrm{P} 4, f_{\text {scatt }}(80 \%) \sim 2.7$ is similar to the value determined by Kotchenruther et al. (1999) for aerosols from both anthropogenic and marine influences, in agreement with the air mass origin. The $f_{\text {scatt }}(80 \%) \sim 4.7$ retrieved for P5 is particularly high. Similar values have nonetheless been previously assessed by Covert et al. (1972) for sea-salt or by Boucher and Anderson (1995) for $\left(\mathrm{NH}_{4}\right)_{2} \mathrm{SO}_{4}$. We note that the latter is the dominant salt $(82 \%)$ present in the aerosol studied here (Fig. 10).

Hänel (1976) proposed a parameterisation of $f_{\text {scatt }}(R H)$ which has been used by many investigators (Covert et al., 1972; Boucher and Anderson, 1995; Ross and Hobbs, 1998; Kotchenruther et al., 1999; Gasso et al., 2000). This parameterisation, which assumes that the growth of the aerosol size with $R H$ is steady with no abrupt change and which is generally applied to the increasing $R H$ part of the cycle, is given by:

$f_{\text {scatt }}(R H)=(1-R H)^{-\gamma}$

where $\gamma$ is the Hänel scattering growth coefficient. If we use a different reference value $\sigma_{\text {scatt,ref corresponding to }}$ $R H=R H_{\text {ref }}$, instead of the dry value, then (10) becomes:

$f_{\text {scatt }}(R H)=\left((1-R H) /\left(1-R H_{\text {ref }}\right)\right)^{-\gamma}$

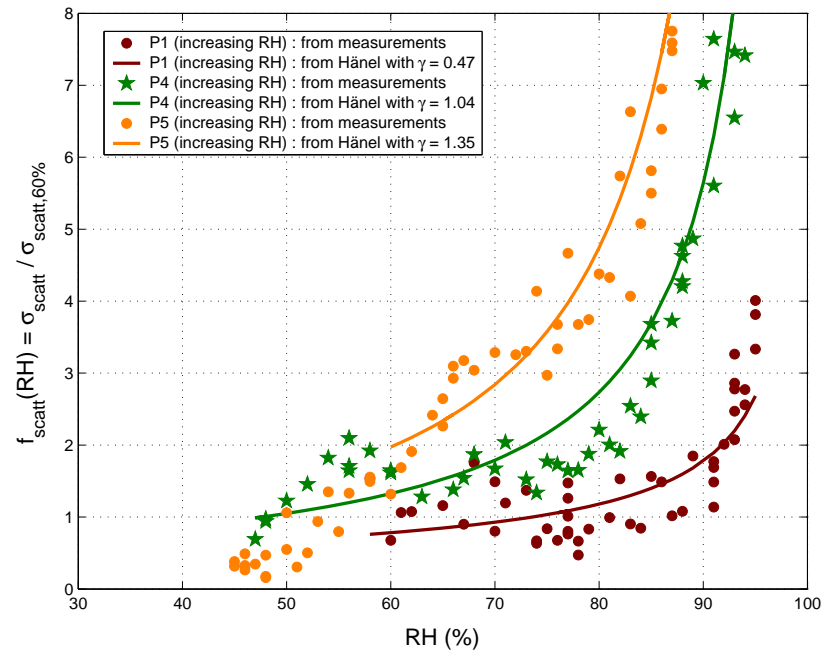

Fig. 12. Growth in aerosol scattering cross section as a function of increasing $\mathrm{RH}$ for the four time periods P1, P3, P4, and P5. Solid lines represent the Hänel (1976) parameterisation fit of the measurements. Colours identify the sampling filters (see Sect. 4.1). The circle and star symbols indicate a salt mixture of Type 1 and Type 3 (see Sect. 4.2.2).

The values of $\gamma$ for P1, P4 and P5 are thus assessed and are given in the last column of Table 4 . For P3, it was difficult to obtain a meaningful fit of the measured $f_{\text {scatt }}(R H)$ values due to their weak evolution, even at high $R H$ values. These scattering growth coefficients are generally larger than the ones found in the literature. The corresponding $f_{\text {scatt }}$ fits are drawn in solid lines in Fig. 12. Due to the Hänel model hypothesis of continuous growth, the more the aerosol presents a pronounced deliquescence (as for P5), the more the Hänel parameterisation over-estimates $f_{\text {scatt }}$ in the deliquescence and dry state $R H$ range. 


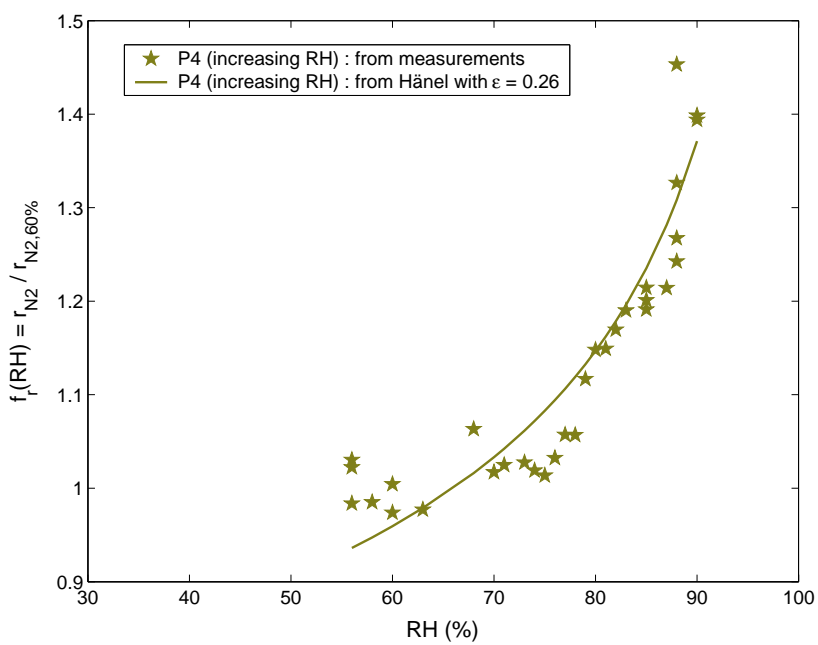

Fig. 13. Growth in aerosol size as a function of increasing $R H$ for the P4. Colours identify the sampling filters (see Sect. 4.1). The star symbol indicates a salt mixture of Type 3 (see Sect. 4.2.2). The solid lines represent the Hänel (1976) parameterisation fit of the measurements.

\subsubsection{Aerosol size growth factor $f_{r}(R H)$}

The aerosol size growth factor, $f_{r}(R H)$, is similarly defined as the ratio between the wet and the quasi-dry modal radius:

$f_{r}(R H)=\frac{r}{r_{\text {ref }}}$

where $r_{\text {ref }}$ is the radius in $R H_{\text {ref }}$ condition. Since only the second mode has been shown to be hygroscopic, the radius used is $r_{N 2}$. P4 is the only case which presents enough $r_{N 2}$ values for a wide enough range of $R H$. The corresponding $f_{r}(R H)$ and $f_{r}(90 \%)$ values are respectively given in Fig. 13 and Table 5. $f_{r}(90 \%) \sim 1.42$ for P4 lies in between the $f_{r}(90 \%)$ values for "less hygroscopic" and "more hygroscopic" aerosols of Swietlicki et al. (2000). It is also close the value retrieved by Weingartner et al. (2002) in the free troposphere.

Hänel (1976) also proposed a parameterisation of $f_{r}(R H)$ given by:

$f_{r}(R H)=(1-R H)^{-\varepsilon}$

where $\varepsilon$ is the Hänel size growth coefficient. As above, if another reference value at $R H_{\text {ref }}$ is used instead of a dry value, (13) becomes:

$$
f_{r}(R H)=\left((1-R H) /\left(1-R H_{\mathrm{ref}}\right)\right)^{-\varepsilon}
$$

The best fit of the P4 measurements leads to $\varepsilon=0.26$ with a standard deviation close to 0.02 . The corresponding $f_{r}(R H)$ is plotted as a solid line in Fig. 13. This $\varepsilon$ value for P4 is coherent with the one retrieved by Chazette and Liousse (2001) for Thessaloniki (Table 5), where the aerosols are from marine and anthropogenic sources, and remains comparable to

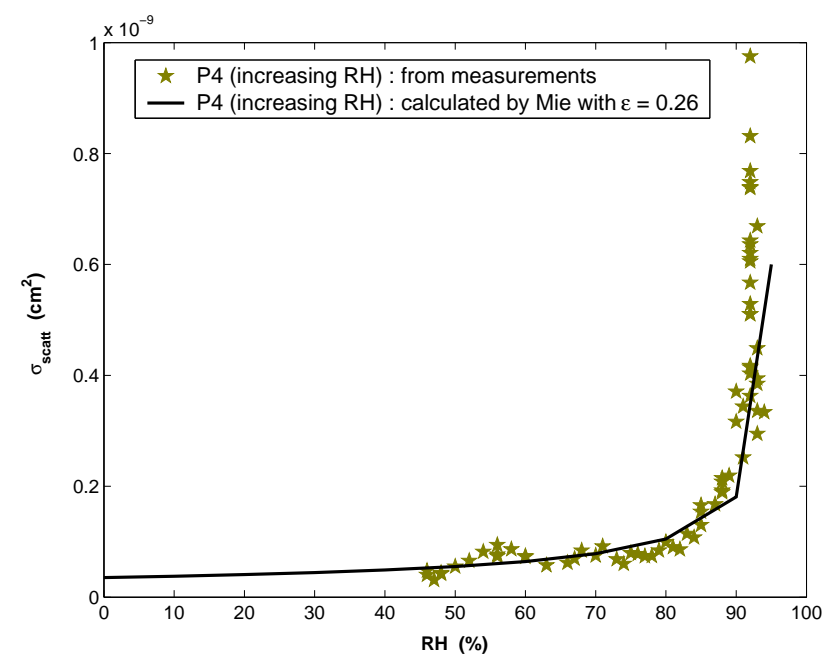

Fig. 14. $\sigma_{\text {scatt }}(R H)$ values retrieved from nephelometer measurements and those calculated from Mie theory by using the Hänel growth factor $\varepsilon$.

the results of Weingartner et al. (2002) for aerosols in the free troposphere.

5.1.3 Coherence between $f_{\text {scatt }}(R H)$ and $f_{r}(R H)$ parameterisations

$\sigma_{\text {scatt }}(R H)$ can also be estimated using $r_{N 2}(R H)$ and Mie theory in order to check the coherence of the two above parameterisations; $\sigma_{\text {scatt }}$ values measured by the nephelometer can thus be compared to those calculated from the retrieved size distribution $\rho_{N}(r)$. Such a closure approach requires the characteristics of the three modes of $\rho_{N}(r)$ and the corresponding aerosol complex refractive indexes, given that the second mode is supposed to be hygroscopic. Similar studies were performed by Wex et al. (2002) and, Quinn and Coffman (1998) in ambient RH. The second mode is thus dependent on $R H$ via the aerosol size growth coefficient $\varepsilon$. For this second hygroscopic mode, a wet refractive index $n_{2 \text {, wet }}$, function of $\varepsilon$ and $\mathrm{RH}$, is given by (Hänel, 1976):

$n_{2, \text { wet }}=n_{\mathrm{H}_{2} \mathrm{O}}+\left(n_{2, \text { dry }}-n_{\mathrm{H}_{2} \mathrm{O}}\right)(1-R H)^{-3 \varepsilon}$

where $n_{2, \text { dry }}=1.53-0.005 i$ and $n_{\mathrm{H}_{2} \mathrm{O}}=1.33-10^{-8} i$ are the dry WS (Voltz, 1973) and the water refractive indexes, respectively. For the first mode, supposed to be composed of POM, the refractive index is taken as $n_{1}=1.55-0.005 i$ (Chazette and Liousse, 2001) and for the third mode, assumed to contain mineral components, we chose $n_{3}=1.5-0.01 i$ (Chazette and Liousse, 2001).

Figure 14 shows the particular case of P4 for which $\varepsilon$ could be assessed. The good agreement between the $\sigma_{\text {scatt }}$ nephelometer measurements and the Mie theory results (with $\varepsilon \sim 0.26)$ proves the coherence of $\sigma_{\text {scatt }}(R H)$ and $r_{N 2}(R H)$ for most of the ambient $R H$ range and thus the predominance 
Table 5. Measured size growth factor $f_{r}(90 \%)$ and size growth coefficient $\varepsilon$ for the present work and from other authors.

\begin{tabular}{|c|c|c|c|c|c|}
\hline Authors & Location & $\begin{array}{l}\text { Radius } \\
(\mu \mathrm{m})\end{array}$ & Characteristics & $f_{r}(90 \%)$ & $\varepsilon$ \\
\hline Weingartner et al. (2002) & Jungfrauroch (Germany) & $\begin{array}{l}0.050 \\
0.100 \\
0.250\end{array}$ & In free troposphere & $\begin{array}{l}1.44 \\
1.49 \\
1.53\end{array}$ & $\begin{array}{l}0.191 \\
0.210 \\
0.223\end{array}$ \\
\hline Baltensperger et al. (2002) & Bresso (Italy) & $\begin{array}{l}0.025 \\
0.1\end{array}$ & During smog events & $\begin{array}{l}1.02 \\
1.24\end{array}$ & - \\
\hline Berg et al. (1998) & Pacific ocean & $\begin{array}{l}0.035 \\
0.05 \\
0.075 \\
0.165\end{array}$ & $\begin{array}{l}\text { Marine aerosols for } \\
\text { non-sea-salt sulphate }\end{array}$ & $\begin{array}{l}1.56 \\
1.59 \\
1.61 \\
1.63\end{array}$ & - \\
\hline Swietlicki et al. (2000) & $\begin{array}{l}\text { Punte del Hidalgo, } \\
\text { (Tenerife) }\end{array}$ & 0.073 & $\begin{array}{l}\text { Marine aerosols + } \\
\text { anthropogenic } \\
\text { More hygroscopic } \\
\text { Less hygroscopic } \\
\text { Hydrophobic }\end{array}$ & $\begin{array}{l}1.65 \\
1.32 \\
1.11\end{array}$ & $\begin{array}{l}- \\
- \\
-\end{array}$ \\
\hline $\begin{array}{l}\text { Chazette and Liousse } \\
(2001)\end{array}$ & Thessaloniki (Greece) & & $\begin{array}{l}\text { Anthropogenic } \\
\text { Traffic and industries } \\
\text { with marine influence }\end{array}$ & 2.2 & 0.25 \\
\hline This work & Saclay (France) & 0.080 & $\mathrm{P} 4$ & 1.42 & 0.26 \\
\hline
\end{tabular}

of the accumulation mode on the hygroscopic behaviour of the aerosol optical properties.

\subsection{Coherence with the ISORROPIA model}

\subsubsection{Aerosol water content factor $f_{\mathrm{H}_{2} \mathrm{O}}(R H)$}

As for $f_{\text {scatt }}(R H)$ and $f_{r}(R H)$, the increase of the aerosol water mass content with $R H$ can be characterized by the ratio $f_{\mathrm{H}_{2} \mathrm{O}}(R H)=m_{\mathrm{H}_{2} \mathrm{O}}(R H) / M_{\text {dry }}$, where $M_{\text {dry }}$ is the dry aerosol mass concentration and $m_{\mathrm{H}_{2} \mathrm{O}}(R H)$ is the water mass concentration of the wet aerosol. The $f_{\mathrm{H}_{2} \mathrm{O}}(80 \%)$ values, determined from the increasing $R H$ part of $m_{\mathrm{H}_{2} \mathrm{O}}(R H)$, are summarized in Table 6 for the five time periods. These values are twice as large as those retrieved by Hänel (1967) for aerosols emitted by an industrial area.

According to Hänel (1967), $f_{\mathrm{H}_{2} \mathrm{O}}$ is a function of $R H$ following the relation:

$f_{\mathrm{H}_{2} \mathrm{O}}(R H)=\mu \frac{R H}{(1-R H)}$

where $\mu$ is the aerosol mass increase coefficient. The $\mu$ values for the five cases, obtained by fitting the $m_{\mathrm{H}_{2} \mathrm{O}} / M_{\text {dry }}$ values, are given in the last column of the Table 6 . The best fits are obtained with correlation coefficients greater than 0.98 . These $\mu$ values lie in between the results of Hänel (1967) $(\sim 0.14)$ and those of Chazette and Liousse $(2001)(\sim 0.48)$ for the city of Thessaloniki, where aerosols from both industries and traffic are mixed with sea salt. The standard deviation of the retrieved $\mu$ has been assessed, through a Monte Carlo approach, to be close to 0.07 .

\subsubsection{Coherence between $\varepsilon$ and $\mu$ retrievals}

This last Hänel parameterisation provides a means for checking the overall coherence between $m_{\mathrm{H}_{2} \mathrm{O}}(R H), \sigma_{\text {scatt }}(R H)$, and $r_{N 2}(R H)$. Another expression of $f_{r}(R H)$ in terms of the aerosol mass increase coefficient $\mu$ (Hänel, 1979) is:

$f_{r}(R H)=\left(1+\frac{d_{\mathrm{dry}}}{d_{\mathrm{H}_{2} \mathrm{O}}} \mu \frac{R H}{(1-R H)}\right)^{1 / 3}$

where $d_{\text {dry }}$ is the density of the dry particle and $d_{\mathrm{H}_{2} \mathrm{O}}$ the water vapour density $\left(1 \mathrm{~g} \mathrm{~cm}^{-3}\right)$. If a reference value $R H_{\text {ref }}$ is considered, (17) becomes:

$f_{r}(R H)=\left(1+\frac{d_{\text {dry }}}{d_{\mathrm{H}_{2} \mathrm{O}}} \mu \frac{R H}{(1-R H)}\right)^{1 / 3} /\left(1+\frac{d_{\text {dry }}}{d_{\mathrm{H}_{2} \mathrm{O}}} \mu \frac{R H_{\mathrm{ref}}}{\left(1-R H_{\mathrm{ref}}\right)}\right)^{1 / 3}$

The aim is to compare $f_{r}(R H)$ given by (14) in terms of the size growth coefficient $\varepsilon$ with $f_{r}(R H)$ given by (18) in terms of the mass increase coefficient $\mu$. Considering the case of $\mathrm{P} 4$, where the widest range of $r_{N 2}$ data against $R H$ is available, $f_{r}(R H)$ has been calculated using the two approaches. This is shown in Fig. 15 for $\mu \sim 0.23$ and $\varepsilon \sim 0.26$. An excellent agreement is found between the results of the two methods, even if the $f_{r}(R H)$ from $\mu$ is slightly over-estimated below $R H \sim 60 \%$, due to the existence of the deliquescence process. The coherence between $m_{\mathrm{H}_{2} \mathrm{O}}(R H)$ and $r_{N 2}(R H)$ behaviours shows that the aerosol water uptake results from ISORROPIA modelling, which uses chemical analysis data as input, are in good agreement with the evolution of the measured modal radius of the accumulation mode with increasing $R H$. 
Table 6. Water mass content factor $f_{\mathrm{H}_{2} \mathrm{O}}(80 \%)$ and mass increase coefficient $\mu$ for the present work and from other authors.

\begin{tabular}{llllll}
\hline Authors & Location & Radius $(\mu \mathrm{m})$ & Characteristics & $f_{\mathrm{H}_{2} \mathrm{O}}(80 \%)$ & $\mu$ \\
\hline Hänel (1967) & Mainz, Germany & $0.15-0.5$ & Industrial & 0.524 & 0.14 \\
Chazette and Liousse (2001) & Thessaloniki & & POM & - & 0.47 \\
& & & WS & & 0.49 \\
This work & Saclay, France & 0.08 & P1 & 1.1 & 0.23 \\
& & & P2 & 1.25 & 0.37 \\
& & & P3 & 1.1 & 0.23 \\
& & P4 & 1.2 & 0.23 \\
& & P5 & 1.1 & 0.23 \\
\hline
\end{tabular}

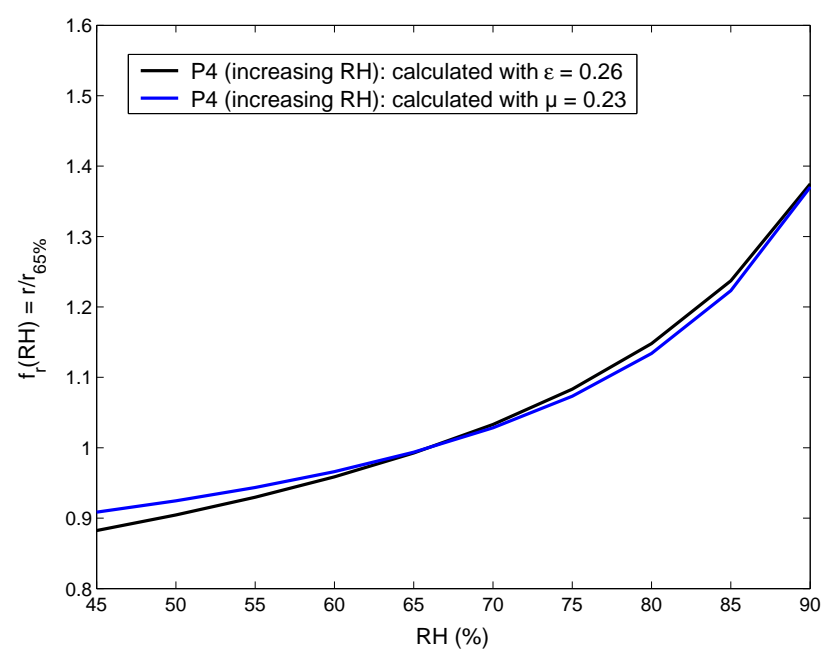

Fig. 15. Comparison between $f_{r}(R H)$ from number size distributions with $\varepsilon=0.26$ and $f_{r}(R H)$ from aerosol water content with $\mu=0.23$.

\subsubsection{Evidence of the hysteresis cycle}

The experimental data of $\sigma_{\text {scatt }}(R H)$ for the time periods $\mathrm{P} 4$ and P5 (Figs. 2d, e) follow a pattern very similar to a hysteresis cycle. However, such sensitivity to $R H$ may result from modifications of various structural or chemical properties of the aerosol or from external parameters. One must thus verify that either the latter did not change significantly or that any other significant modification between the rising and the falling $R H$ parts of the cycle is not responsible for such a pattern. The use of the scattering cross-section (Sect. 3.1) discards any influence of the total number concentration variability. We have seen that neither the deliquescence process sensitivity to the ambient temperature variability (Sect. 3.3), nor the number size distribution characteristics, other than the modal radius of the accumulation mode $r_{2}$ (Sect. 3.4), have enough influence on the $R H$ dependency to explain such a pattern. The last possible cause may come from a

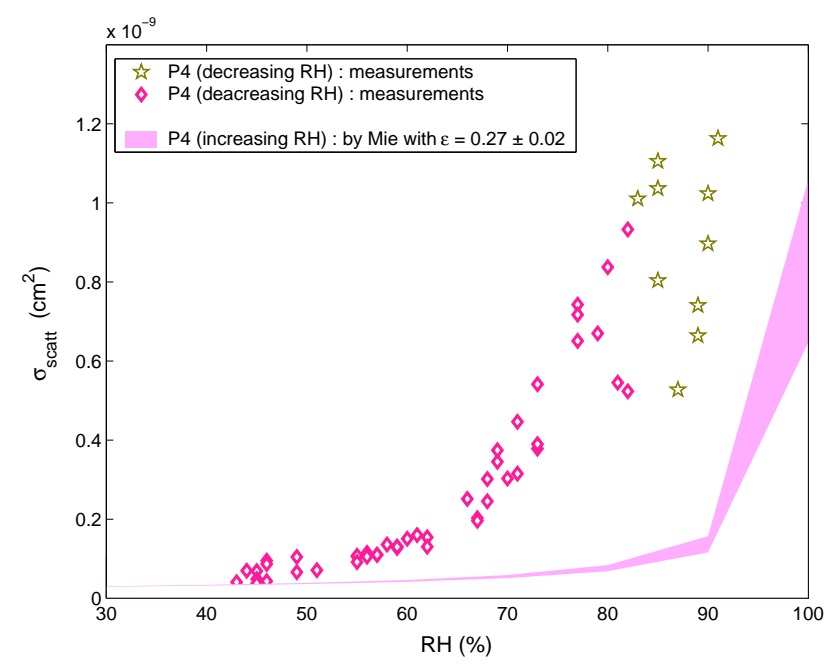

Fig. 16. Evidence of the hysteresis phenomenon for the $\mathrm{P} 4$ time period. The shaded area corresponds to $\sigma_{\text {scatt }}(R H)$ retrieved from the chemical composition of the aerosols sampled during the decreasing $R H \sigma_{\text {scatt }}(R H)$ measurements (open symbols).

time evolution of the chemical composition of the aerosol. In that respect, the time period $\mathrm{P} 4$ is a particularly interesting case, with a noticeable difference in chemical composition (see Fig. 6, 9, 10 and Sect. 4) between the beginning and the end of the time period.

We thus use the chemical composition of the decreasing $R H$ part of the P4 cycle as ISORROPIA input to retrieve the corresponding $R H$ evolution of the water mass content $m_{\mathrm{H}_{2} \mathrm{O}}(R H)$. The parameterisations of the previous section, whose coherence has been checked, lead to a value of $\mu=0.32 \pm 0.07$ for $m_{\mathrm{H}_{2} \mathrm{O}}(R H)$ and, through Eq. (14) and (18), to a value $\varepsilon=0.27 \pm 0.02$ for the size growth factor $f_{r}(R H)$. The corresponding $\sigma_{\text {scatt }}(R H)$ have been retrieved (see Sect. 5.1.3) and are displayed as a shaded area in Fig. 16, together with the measured $\sigma_{\text {scatt }}(R H)$ values during the decreasing $R H$ part of the time period. It seems clear that whatever the aerosol chemical composition is, its impact 
on the $R H$ aerosol size growth dependency is not sufficient enough to explain the high values of $\sigma_{\text {scatt }}(R H)$ during the falling $R H$ part of the diurnal cycle. Thus, this branch of the $R H$ cycle can be identified to the super-saturated state of the hysteresis cycle.

\section{Conclusions}

In this paper, we have studied the effect of $R H$ on various aerosol parameters. We worked with independent optical, size distribution and chemical data measured in ambient atmosphere at Saclay during the ESQUIF program. The hygroscopic behaviour of the accumulation mode of the aerosol produced in the Paris area has been established. However, the overall aerosol hygroscopicity is found to be clearly dependent on both air mass origin and history. Based on the Hänel model, independent parameterisations with $R H$ of the scattering cross section, the modal radius of the accumulation mode and the water uptake of the aerosol have been established. For the first time, a crosscheck of these parameterisations has been performed and shows that the hygroscopic behaviour of the accumulation mode can be coherently characterized by combined optical, size distribution and chemical measurements. Moreover, the existence of a hysteresis phenomenon in the hygroscopic growth cycle has been established unambiguously.

This work demonstrates the importance of a wide instrumental synergy for pollution aerosol survey, even at the surface level. The number of samples available to conduct this study does not permit to sample all possible air mass situations nor all different aerosol chemical compositions around Paris. Complementary studies are necessary and will be conducted over the next years in Paris and its suburbs. Nevertheless, the first approach presented here will permit to use such parameterisations in chemistry and transport mesoscale models, and to ameliorate, in the near future, pollution forecasting in the Paris area (Vautard et al., 2003a, 2003b). Moreover, it will contribute to a better interpretation of optical measurements from space borne instruments and it confirms the importance of taking into account the relative humidity effect on aerosol, together with its history, in the estimation of the radiative budget.

Acknowledgements. This work was supported by the Programme National de Chimie Atmosphérique, the Institut National des Sciences de l'Univers (INSU) and the Commissariat à l'Energie Atomique. Part of this work was granted by PSA Peugeot Citroën. The authors thank Elizabeth Devlin for her careful reading of the manuscript. They also acknowledge Hélène Cachier and Stéphane Alfaro for their help in the filters chemical analysis. This is LSCE contribution number 1412

Edited by: G. Feingold

\section{References}

Adams, P. J., Seinfeld, J. H., and Koch, D. M: Global concentrations of tropospheric sulfate, nitrate, an ammonium aerosol simulated in a general circulation model, J. Geophys. Res., 104(D11), 13 791-13 823, 1999.

Andrews, E. and Larson, S. M.: Effect of Surfactant Layers on the Size Changes of Aerosol Particles as a Function of Relative Humidity, Environ. Sci. Technol., 27, 857-865, 1993.

Baltensperger, U., Streit, N., Weingartner, E., Nyeki, S., Prévôt, S. H., Van Dingenen, R., Virkula, A., Putaud, J. P., Even, A., ten Brink, H., Blatter, A., Neftel, A., and Gäggeler, H. W.: Urban and rural aerosol characterization of summer smog events during the PIPAPO field campaign in Milan, Italy, J. Geophys. Res., 107(D22), 8193, doi:10.1029/2001JD001292, 2002.

Bates, T. S, Quinn, P. K., Coffman, D. J., Covert, D. S., Miller, T. L., Johnson, J. E., Carmichael, G. R., Uno, I, Guazzotti, S. A., Soderman, D. A., Prather, K. A., Rivera, M., Russel, L. M., and Merrill, J.: Marine boundary layer dust and pollutant transport associated with the passage of a frontal system over eastern Asia, J. Geophys. Res., 109, D19S19, doi:10.1029/2006JD004094, 2004.

Berg, O. H., Swietlicki, E., and Kredci, R.: Hygroscopic growth of aerosol particles in the marine boundary layer over the Pacific and Southern Oceans during the first aerosol characterization experiment (ACE 1), J. Geophys. Res., 103(D13), 16 535-16546, 1998.

Bodhaine, B. A., Ahlquist, N. C., and Schnell, R. C.: Threewavelength nephelometer suitable for aircraft measurements of background aerosol scattering coefficient, Atmos. Environ., 10, 2268-2276, 1991.

Boucher, O. and Anderson, L.: General circulation model assessment of the sensitivity of direct climate forcing by anthropogenic sulfate aerosols to aerosol size and chemistry, J. Geophys. Res., 100(D12), $26117-26134,1995$.

Brémond, M. P., Cachier, H., and Buat-Ménard, P.: Particulate carbon in the Paris region atmosphere, Env. Techn. Lett., 10, 339346, 1989.

Cachier, H., Brémond, M. P., and Buat-Ménard, P: Determination of atmospheric soot carbon with a simple thermal method, Tellus, 41B, 379-390, 1989.

Charlson, R. J., Covert, D. S., and Larson, T. V.: Observation of the effect of humidity on light scattering by aerosols, in: Hygroscopic Aerosols, edited by: Rukube, T. H. and Deepak, A., A Deepak, Hampton, VA, 35-44, 1984.

Chazette, P., David, C., Lefrère, J., Godin, S., and Mégie, G.: Comparative lidar study of the optical, geometrical, and dynamical properties of stratospheric post-volcanic aerosols, following the eruptions of El Chichon and Mount Pinatubo, J. Geophys. Res., 100(D11), 23 195-23 208, 1995.

Chazette, P. and Liousse, C.: A case study of optical and chemical apportionment for urban aerosols in Thessaloniki, Atmos. Environ., 35, 2497-2506, 2001.

Chazette, P., Randriamiarisoa, H., Sanak, J., Couvert, P., and Flamant, C.: Optical properties of urban aerosol from airborne and ground based in situ measurements performed during the ESQUIF program, J. Geophys. Res., 110, D02206, doi:10.1029/2004JD004810, 2005.

Carrico, C. M., Rood, M. J., Ogren, J. A., Neusüß, C., Wiedensohler, A., and Heintzenberg, J.: Aerosol optical properties at 
Sagres, Portugal during ACE-2, Tellus B, 52, 2, 694-715, 2000.

Carrico, C. M., Bergin, M. H., Xu, J., Baumann, K., and Maring, H.: Urban aerosol radiative properties: Measurements during the 1999 Atlanta Supersite Experiment, J. Geophys. Res, 108, D78422, doi:10.1029/2001JD001222, 2003.

Countess, R. J., Wolff, G. T., and Cadle, S. H.: The denver winter aerosol: a comprehensive chemical characterization, JAPCA J. Air Waste, 30, 1194-1200, 1980.

Covert, D. S., Charlson, R. J., and Ahlquist, N. C.: A study of the relationship of chemical composition and humidity to light scattering by aerosols, J. Appl. Meteorol., 11, 968-976, 1972.

Covert, D. S., Waggoner, A. P., Weiss, R. E., Ahlquist, N. C., and Charlson, R. J.: Atmospheric aerosols, humidity and visibility, in character and Origin of Smog Aerosols, John Wiley, New York, 1979.

Cruz, C. N. and Pandis, S. N.: The effect of organic coatings on the cloud condensation nuclei activation of inorganic atmospheric aerosol, J. Geophys. Res., 103(D11), 13 111-13 123, 1998.

Cruz, C. N. and Pandis, S. N.: Deliquescence and hygroscopic growth of mixed inorganic-organic atmospheric aerosol, Environ. Sci. Technol., 34, 4313-4319, 2000.

Dick, W. D., Saxena, P., and McMurry, P. H.: Estimation of Water Uptake by Organic Compounds in Submicron Aerosols Measured during the Southeastern Aerosol and Visibility Study, J. Geophys. Res., 105(D1), 1471-1480, 2000.

Dougle, P. G., Veefkind, J. P., and ten Brink, M.: Crystallisation of mixtures of ammonium nitrate, ammonium sulfate and soot, J. Aerosol Sci., 29, 375-386, 1998.

Draxler, R. R. and Hess, G. D.: An overview of the Hysplit_4 modeling system for trajectories, dispersion, and deposition, Aust. Met. Mag., 47, 295-308, 1998.

Ferron, G. A., Karg, E., Busch, B., and Heyder, J.: Ambiant particles at an urban, semi-urban and rural site in Central Europe: hygroscopic properties, Atmos. Environ., 39, 343-352, 2005.

Gasso, S., Hegg, D. A., Covert, D. S., Collins, D., Noone, K. J., Oström, E., Schmid, B., Russel, P. B., Livingston, J. M., Durkee, P. A., and Josson, H.: Influence of humidity on the aerosol scattering coefficient and its effect on the upwelling radiance during ACE-2, Tellus, 52B, 546-567, 2000.

Hameri, K., Rood, M. J., and Hansson, H. C.: Hygroscopic Properties of a $\mathrm{NaCl}$ Aerosol Coated with Organic Compounds, J. Aerosol Sci., 23, S437-S440, 1992.

Hand, J. L. and Kreidenweis, S. M: A new method for retrieving particle refractive index and effective density from aerosol size distribution data, Aerosol Sci. Technol., 36, doi:10.1080/02786820290092276, 1012-1026, 2002.

Hänel, G.: The real part of the mean complex refractive index and the mean density of samples of atmospheric aerosol particles, Tellus, 3, 371-3779, 1967.

Hänel, G.: The properties of atmospheric aerosol particles as functions of the Relative humidity at thermodynamic equilibrium with the surrounding moist air, Adv. Geophys., 19, 73-188, 1976.

Hansson, H.-C., Wiedensohler, A., Rood, M. J., and Covert, D. S.: Experimental Determination of the Hygroscopic Properties of Organically Coated Aerosol Particles, J. Aerosol Sci., 21, S241S244, 1990.

Haywood, J. M., Roberts, D. L., Slingo, A., Edwards, J. M., and Shine, K. P.: General circulation model calculations of the direct radiative forcing by anthropogenic sulphate and fossil-fuel soot aerosol, J. Clim., 10, 1562-1577, 1997.

Hegg, D. A., Livingston, J., Hobbs, P. V., Novakov, T., and Russel, P.: Chemical apportionment of aerosol column optical depth off the mid-Atlantic coast of the United States, J. Geophys. Res., 102(D21), 25 293-25 303, 1997.

Hobbs, P. V., Reid, J. S., Kotchenruther, R. A., Ferek, R. J., and Weiss, R.: Direct radiative forcing by smoke from biomass burning, Science, 275, 1776-1778, 1997.

Intergovernmental Panel on Climate Change: "Climate change 2001", in: The Science of Climate Change, edited by: Houghton, J. T., Meira Filho, L. G., Callander, B. A., Harris, N., Kattenberg, A., and Maskell, K., Cambridge U. Press, London, 2001.

Jaffrezo, J.-L., Davidson, C. I., Legrand, M., and Dibb, J. E.: Sulfate and MSA in the air snow on the Greenland Ice Sheet, J. Geoghys. Res., 99(D1), 1241-1254, 1994.

Junge, C.: Air chemistry and radioactivity, Academic press, San Diego, Calif., 133-

blackboxlast page?, 1963.

Kleindienst, T. E., Smith, D. F., Li, W., Edney, E. O., Driscoll, D. J., Speer, R. E., and Weathers, W. S.: Secondary Organic Aerosol Formation from the Oxidation of Aromatic Hydrocarbons in the Presence of Dry Submicron Ammonium Sulphate Aerosol, Atmos. Env., 33, 3669-3681, 1999.

Kotchenruther, R. A., Hobbs, P. V., and Hegg, D. A.: Humidification factors for atmospheric aerosol off the mid-Atlantic coast of United States, J. Geophys. Res., 104(D2), 2239-2252, 1999.

Kulmala, M., Laaksonen, A., Korhonen, P., Vesala, T., and Ahonen, T.: The effect of atmospheric nitric acid vapor on cloud condensation nucleus activation, J. Geophys. Res., 98(D12), 22 94922 958, 1993.

Larson, T. V. and Taylor, G. S.: On the evaporation of $\mathrm{NH}_{4} \mathrm{NO}_{3}$ aerosol, Atmos. Environ., 17, 2489-2595, 1983.

Lenoble, J.: Atmospheric radiative transfer, A DEEPAK Publishing, Hampton, USA, 1993.

Liousse, C., Penner, J. E., Chuang, C. C., Walton, J. J., and Eddleman, H.: A global three-dimensional model study of carbonaceous aerosols, J. Geophys. Res., 101(D14), 19411-19432, 1996.

Liu, B. H. and Lee, K. W.: Efficiency of membrane and nuclepore filters for submicrometer aerosols, Environ. Sci. Tech., 10, 345350, 1976.

Malm, W. C. and Kreidenweis, S. M.: The effects of models of aerosol hygroscopicity on the apportionment of extinction, Atmos. Environ., 31, 13, 1965-1976, 1997.

Malm, W. C. and Day, D. E.: Estimates of Aerosol Species Scattering Characteristics as a Function of Relative Humidity, Atmos. Environ., 35, 2845-2860, 2001.

McInnes, L. M., Bergin, M. H., Ogren, J. A., and Schwartz, S. E.: Apportionment of light scattering and hygroscopic growth to aerosol composition, Geophys. Res. Lett., 25, 513-516, 1998.

McMurry, P. and Stolzenburg, M. R.: On the sensitivity of particle size to relative humidity for Los Angeles aerosols, Atmos. Environ., 23, 497-507, 1989.

Menut, L., Vautard, R., Flamant, C., Abonnel, A., Beekmann, M., Chazette, P., Flamant, P. H., Gombert, D., Guédalia, D., Kley, D., Lefebvre, M. P., Lossec, B., Martin, D., Mégie, G., Perros, P., Sicard, M., and Toupance, G.: Measurements and modelling of atmospheric pollution aver the Paris area: An overview of the 
ESQUIF project, Ann. Geophys., 18, 1467-1481, 2000.

Nenes, A., Pandis, S., and Pilinis, C.: ISORROPIA: A new thermodynamic equilibrium model for multiphase multi-component inorganic aerosols, Aquat. Geoch., 123-152, 1998.

Orr, C., Hurd, F. K., and Corbett, W. J.: Aerosol size and relative humidity, J. Coll. Sci., 13, 472-782, 1958.

Patterson, E. M. and Gillette, D. A.: Commonalities in measured size distributions for aerosols having a soil-derived component, J. Geophys. Res., 82, 2074-2082, 1977.

Potukuchi, S. and Wexler, A.: Identifying solid-aqueous-phase transitions in atmospheric aerosol. I. Neutral acidity solution, Atmos. Environ., 29, 1663-1676, 1995a.

Potukuchi, S. and Wexler, A.: Identifying solid-aqueous-phase transitions in atmospheric aerosol. II. Acidic solutions, Atmos. Environ., 29, 22, 3357-3364, 1995b.

Quinn, P. K. and Coffman, D. J.: Local closure during the First Aerosol Characterization Experiment (ACE 1): Aerosol mass concentration and scattering and backscattering coefficients, J. Geophys. Res., 103(D13), 16575-16596, 1998.

Rood, M. J., Covert, D. S., and Larson, T. V.: Hygroscopic properties of atmospheric aerosol in Riverside, California, Tellus, 39b, 383-397, 1987.

Ross, J. L., Hobbs, P. V., and Holben, B.: Radiative characteristics of regional hazes dominated by smoke from biomass burning in Brazil: Closure tests and direct radiative forcing, J. Geophys. Res., 103(D24), 31 925-31 941, 1998.

Santarpia, J. L., Li, R. H., and Collins, D. R.: Direct measurement of the hydration state of ambient aerosol populations, J. Geophys. Res., 109, D18209, doi:10.1029/2004JD004653, 2004.

Saxena, P., Hildemann, L. M., McMurry, P. H., and Seinfeld, J. H.: Organics alter hygroscopic behavior of atmospheric particles, J. Geophys. Res., 100(D9), 18 755-18 770, 1995.

Seinfeld, J. H. and Pandis, S. N.: From Air Pollution to Climate Change, Atmospheric Chemistry and Physics, John Wiley \& Sons, New York, 1326, 1998.

Sekigawa, K.: Estimation of the volume fraction of water-soluble material in submicron aerosols in the atmosphere, J. Meteorol. Soc. Japan., 61, 359-366, 1983.

Sloane, C. S.: Optical properties of aerosols of mixed composition, Atmos. Environ., 18, 871-878, 1984.

Spann, J. F. and Richardson, C. B.: Measurement of the water cycle in mixed ammonium acid sulphate particles, Atmos. Environ., 19, 819-825, 1985.

Stelson, A. W. and Seinfeld, J. H.: Relative humidity and temperature dependence of the ammonium nitrate dissociation constant, Atmos. Environ., 16, 983-992, 1982.

Swietlicki, E., Zhou, J., Covert, D. S., Hämeri, K., Busch, B., Väkeva, M., Dusek, U., Berg, O. H., Wiedensohler, A., Aalto, P., Mäkelä, J., Martinsson, B. G., Papaspiropoulos, G., Mentes, B., Frank, G., and Stratmann, F.: Hygroscopic properties of aerosol particles in the north-eastern Atlantic during ACE-2, Tellus, 52B, 201-227, 2000.

Tabazadeh, A. and Toon O. B.: The role of ammoniated aerosols in cirrus cloud nucleation, Geophys. Res. Lett., 25, 1379-382, 1998.

Tang, I. N.: On the equilibrium partial pressures of nitric acid and ammonia in the atmosphere, Atmos. Environ., 14, 819-828, 1980a.
Tang, I. N.: Deliquescence properties and particle size change of hygroscopic aerosols, in: Generation of aerosols and facilities for exposure experiments, edited by: Willeke, K., Ann Arbor Science, Ann Arbor, 153-167, 1980b.

Tang, I. N., Wong, W. T., and Munkelwitz, H. R.: The relative importance of atmospheric sulphates and nitrates to visibility reduction, Atmos. Environ., 15, 2763-2471, 1981.

Tang, I. N. and Munkelwitz, H. R.: Composition and temperature dependence of the deliquescence properties of hygroscopic aerosols, Atmos. Environ., 15, 2763-2471, 1993.

Tang, I. N. and Munkelwitz, H. R.: Water activities, densities, and refractive indices of aqueous sulfates and sodium nitrate droplets of atmospheric unimportance, J. Geophys. Res., 99(D9), 18 80118 808, 1994.

Turpin, B. J., Saxena, P., and Andrews, E.: Measuring and simulating particulate organics in the atmosphere: problems and prospects, Atmos. Environ., 34 (18), 2983-3013, 2000.

Turpin, B. J. and Lim, H.: Species contribution to PM2.5 concentrations: Revising common assumptions for estimating organic mass, Aerosol Sci. Technol., 35, 602-610, 2001.

Van Dorland, R., Dentener, F. J., and Lilieveld, J.: Radiative forcing due to tropospheric ozone and sulfate aerosols, J. Geophys. Res. 102(D23), 28 079-28 100, 1997.

Vautard, R., Menut, L., Beekmann, M., Chazette, P., Flamant, P.H., Gombert, D., Guédalia, D., Kley, D., Lefebvre, M. P., Martin, D., Mégie, G., Perros, P., and Toupance, G.: A synthesis of the Air Pollution Over the Paris Region (ESQUIF) field campaign, J. Geophys. Res., 108(D17), 8558, doi:10.1029/2003JD003380, 2003a.

Vautard, R., Martin, D., Beekmann, M., Drobinski, P., Friedrich, R., Jaubertie, A., Kley, D., Lattuati, M., Moral, P., Neininger, B., and Theloke, J.: Paris emission inventory diagnostics from ESQUIF airborne measurements and a chemistry transport model, J. Geophys. Res., 108(D17), 8564, doi:10.1029/2002JD002797, 2003b.

Volz, F. E.: Infrared optical constants of ammonium sulphate, Saharan dust, volcanic pumice and fly-ash, Appl. Opt., 12, 564-568, 1973.

Waggoner, A. P., Weiss, R. E., and Larson, T. V.: In-Situ Rapid Response Measurement of $\mathrm{H}_{2} \mathrm{SO}_{4} /\left(\mathrm{NH}_{4}\right)_{2} \mathrm{SO}_{4}$ Aerosols in Urban Houston: a Comparison with Rural Virginia, Atmos. Environ., 17, 1723-1731, 1983.

Weingartner, E., Gysel, M., and Baltensperger, U.: Hygroscopicity of aerosol particles at low temperatures. 1. New low-temperature H-TDMA instrument: set-up and first applications, Environ. Sci. Technol., 36, 55-62, 2002.

Wex, H., Neusüß, C., Koziar, C., Wendisch, M., Keil, A., and Wiedensohler, A.: In-situ closure studies on scattering, backscattering, and absorption coefficients and their sensitivity, J. Geophys. Res., 107(D21), 8122, doi:10.1029/2000JD000234, 2002.

Wexler, A. S. and Seinfeld, J. H.: Second generation inorganic aerosol model, Atmos. Environ., 25A, 12, 2731-2748, 1991.

Zhang, X. Q., McMurry, P. H., Hering, S. V., and Casuccio, G. S.: Mixing characteristics and water content of submicron aerosols measured in Los Angeles and at the Grand Canyon, Atmos. Environ., Part A, 27, 1593-1607, 1993. 